Florida International University FIU Digital Commons

$1-14-2016$

\title{
Neighborhood-level Determinants of Delayed HIV Diagnosis and Survival among HIV-positive Latinos, Florida 2000-2011
}

Diana M. Sheehan

Florida International University, dshee004@fiu.edu

DOI: $10.25148 /$ etd.FIDC000225

Follow this and additional works at: https://digitalcommons.fiu.edu/etd

Part of the Epidemiology Commons

\section{Recommended Citation}

Sheehan, Diana M., "Neighborhood-level Determinants of Delayed HIV Diagnosis and Survival among HIV-positive Latinos, Florida 2000-2011" (2016). FIU Electronic Theses and Dissertations. 2502.

https://digitalcommons.fiu.edu/etd/2502 


\section{FLORIDA INTERNATIONAL UNIVERSITY}

Miami, Florida

\section{NEIGHBORHOOD-LEVEL DETERMINANTS OF DELAYED HIV DIAGNOSIS} AND SURVIVAL AMONG HIV-POSITIVE LATINOS, FLORIDA 2000-2011

A dissertation submitted in partial fulfillment of the

requirements for the degree of

DOCTOR OF PHILOSOPHY

in

PUBLIC HEALTH

by

Diana Montserrat Sheehan

2016 
To: Dean Tomás R. Guilarte

Robert Stempel College of Public Health and Social Work

This dissertation, written by Diana Montserrat Sheehan, and entitled Neighborhood-level Determinants of Delayed HIV Diagnosis and Survival among HIV-positive Latinos, Florida 2000-2011, having been approved in respect to style and intellectual content, is referred to you for judgment.

We have read this dissertation and recommend that it be approved.

$\begin{array}{r}\hline \text { Frank R. Dillon } \\ \hline \text { Kristopher P. Fennie } \\ \hline \text { Purnima Madhivanan } \\ \hline \text { Mary Jo Trepka, Major Professor }\end{array}$

Date of Defense: January 14, 2016

The dissertation of Diana Montserrat Sheehan is approved.

Dean Tomás R. Guilarte Robert Stempel College of Public Health and Social Work

Andrés G. Gil Vice President for Research and Economic Development Dean of the University Graduate School

Florida International University, 2016 
(C) Copyright 2016 by Diana Montserrat Sheehan

All rights reserved 


\section{DEDICATION}

This dissertation is dedicated to my parents. Without their sacrifice and desire to provide me with the opportunity of a quality education, this work would not have been possible. 


\section{ACKNOWLEDGMENTS}

I would like to thank the Department of Epidemiology, my dissertation committee, and C-SALUD for their generous support throughout my doctoral studies. I would like to express my sincere gratitude to my major professor, Dr. Mary Jo Trepka. Without her guidance, wisdom, and genuine commitment to my success, this work would not have been possible. I would also like to thank Dr. Fennie, who patiently entertained the simplest of analytical questions and provided me with thoughtful advice, and Drs. Dillon and Madhivanan for their feedback and constant positive encouragement. Likewise, without the early and unwavering support of Dr. De La Rosa and C-SALUD, my journey to this point would have been vastly different-not as comprehensive, not as productive, not as rewarding.

In addition, I would like to thank my family. Their support has been vital to maintaining perspective and balance throughout this project. I am deeply grateful to my husband and biggest cheerleader, Michael. My admiration for his hard work, generosity, simplicity, and determination gave me the fuel I needed to complete this work.

Finally, this work was supported by National Institute on Minority Health \& Health Disparities (NIMHD) Award P20MD002288 and 5R01MD004002, and National Institute on Drug Abuse (NIDA) Award F31DA037790. The content is solely the responsibility of the authors and does not necessarily represent the official views of NIMHD, NIDA, or the National Institutes of Health. 


\section{ABSTRACT OF THE DISSERTATION}

\section{NEIGHBORHOOD-LEVEL DETERMINANTS OF DELAYED HIV DIAGNOSIS}

AND SURVIVAL AMONG HIV-POSITIVE LATINOS, FLORIDA 2000-2011

by

\section{Diana Montserrat Sheehan}

Florida International University, 2016

$$
\text { Miami, Florida }
$$

Professor Mary Jo Trepka, Major Professor

The purpose of this study was to estimate disparities in late human immunodeficiency virus (HIV) diagnosis and all-cause mortality among varying populations of HIV-positive Latinos, and to identify neighborhood-level predictors. Florida HIV surveillance data for years 2000-2011 were merged with 2007-2011 American Community Survey (ACS) data. Multilevel logistic regressions were used to estimate adjusted odds ratios (aOR) for late HIV diagnosis (acquired immunodeficiency syndrome within 3 months of HIV diagnosis). Multilevel weighted Cox regressions were used to estimate adjusted hazard ratios (aHR) for mortality.

Of 5522 Latinos diagnosed 2007-2011, males were at increased odds of late diagnosis compared with females (aOR 1.37, 95\% confidence interval [CI] 1.13-1.67). Associated factors included residing in the lowest quartile of neighborhood education for females, and in the 3 highest quartiles of unemployment for males. Foreign-born compared with United States (US)-born Latinos were also at risk (aOR 1.24, 95\% CI 
1.08-1.42). Among foreign-born, residing in areas with $<25 \%$ compared with $\geq 50 \%$ Latinos was a risk factor (aOR 1.37, 95\% CI 1.05-1.79). Among 10,989 Latinos diagnosed 2000-2008, those with injection drug use (IDU) history compared with those without were at increased mortality risk (aHR 1.61, 95\% CI 1.43-1.80). Associated factors for those with IDU history included residing in areas with $\geq 50 \%$ Latinos compared with <25\% Latinos (aHR 1.56, 95\% CI 1.19-2.04), and in rural compared with urban areas (aHR 1.73, 95\% CI 1.06-2.70). Among 4649 Latinos diagnosed 2005-2008, those born in Puerto Rico compared with those born in the US were at increased mortality risk (aHR 2.00, 95\% CI 1.53-2.59). Factors associated with mortality among those born in Puerto Rico included neighborhood poverty (aHR 1.21 per 5 unit increase, 95\% CI 1.08-1.34) and residing in areas with $\geq 50 \%$ compared with $<25 \%$ Latinos (aHR 1.67, 95\% CI 1.01-2.70).

Targeted and improved neighborhood-level HIV diagnosis, care and treatment strategies are warranted for Latinos. Males and foreign-born Latinos are at particular risk of delayed HIV diagnosis. Latinos with IDU history and those born in Puerto Rico are at increased mortality risk after HIV diagnosis. Results suggest that these at-risk groups interact uniquely with their environments and have distinct contributing factors to HIVrelated outcomes. 
CHAPTER PAGE

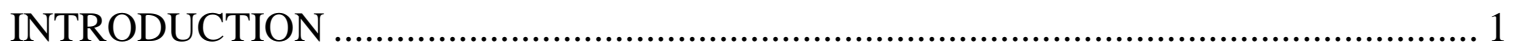

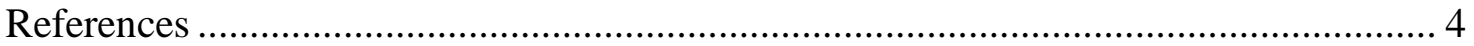

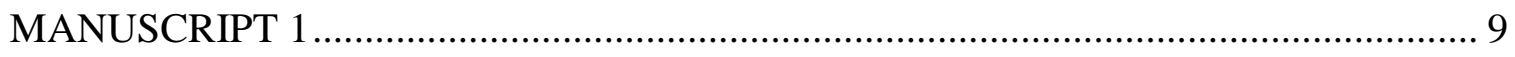

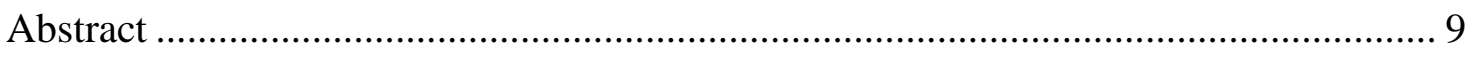

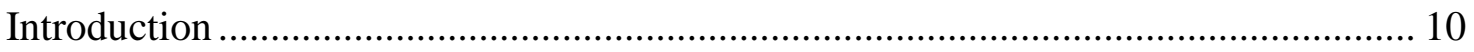

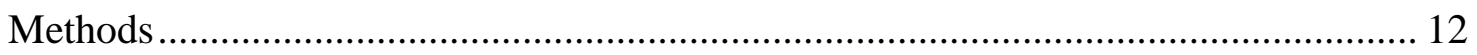

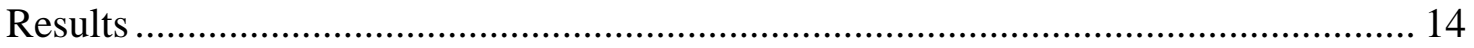

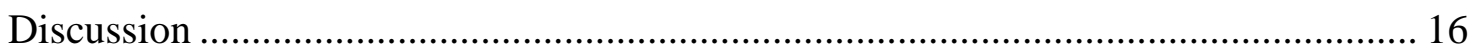

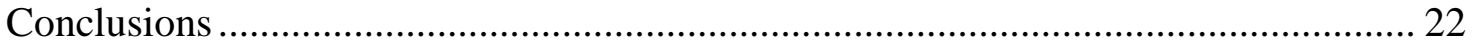

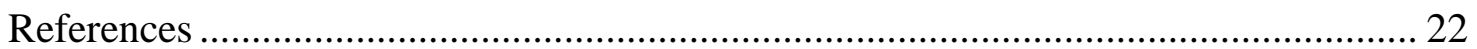

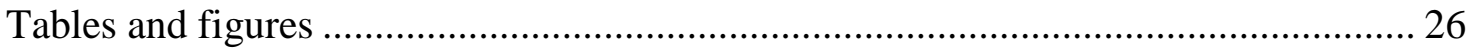

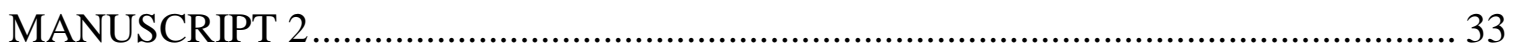

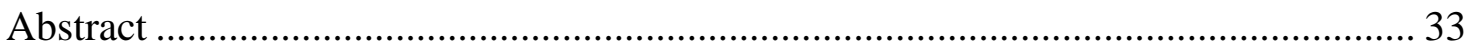

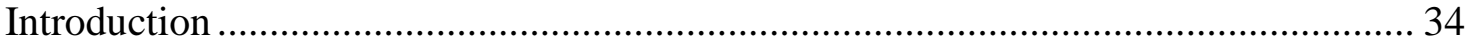

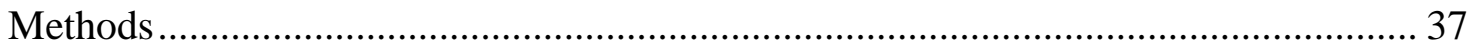

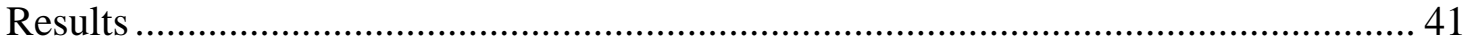

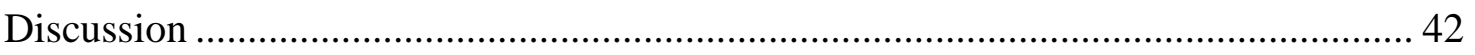

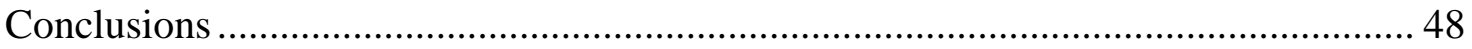

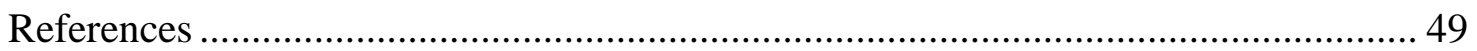

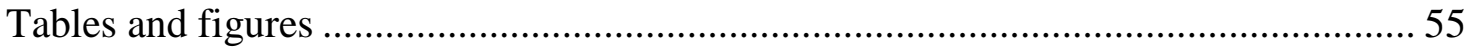

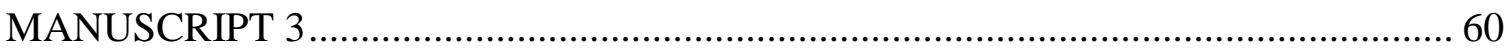

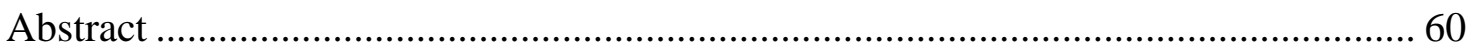

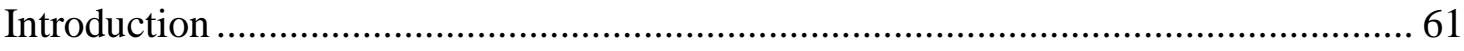

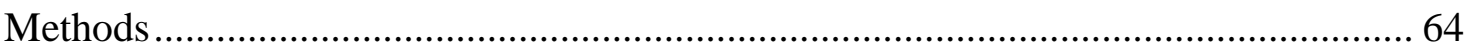




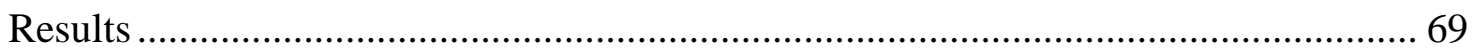

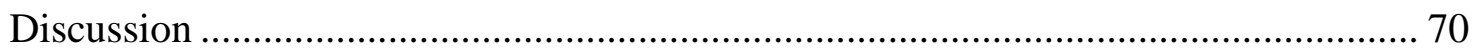

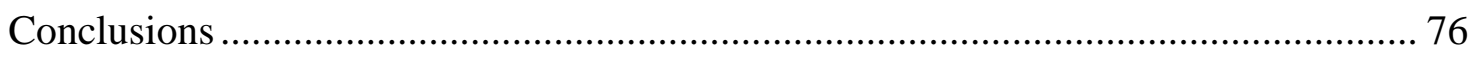

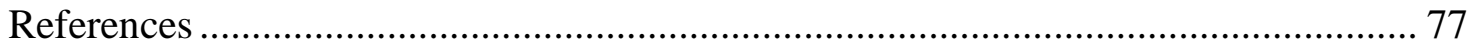

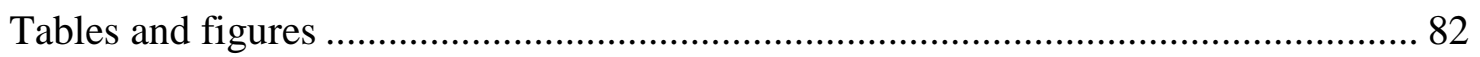

CONCLUSIONS

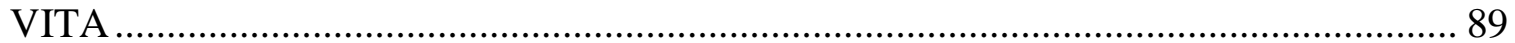




\section{ABBREVIATIONS AND ACRONYMS}

ACS American Community Survey

AIDS Acquired immunodeficiency syndrome

CDC Centers for Disease Control and Prevention

CI Confidence interval

EHARS Enhanced HIV/AIDS Reporting System

HAART Highly active antiretroviral therapy

HR Hazard ratios

HIV Human immunodeficiency virus

IDU Injection drug user

MSM Men who have sex with men

OR Odds ratios

RUCA Rural-Urban Commuting Area

SES Socioeconomic status

US United States

ZCTA Zip code tabulation area 


\section{INTRODUCTION}

The incidence of human immunodeficiency virus (HIV) in the United States (US) is three times higher for Latinos than for non-Latino whites (Centers for Disease Control and Prevention, n.d.). About 20\% of Latinos with HIV are not aware of their HIV status (Chen et al., 2012), and over 40\% are diagnosed with HIV late (acquired immunodeficiency syndrome [AIDS] within 12 months of an HIV diagnosis) (Espinoza et al., 2012). An estimated 49\% of HIV transmissions in the US are from persons unaware of their HIV infection (Hall et al., 2012) who may continue risky sexual and drug-related behaviors, unknowingly putting others at-risk. Late HIV diagnosis and subsequent late treatment, increases the risk of poor health outcomes (Cohen et al., 2011) and doubles the risk of HIV-related mortality (Hanna et al., 2008). Reported predictors of late HIV diagnosis among Latinos include male sex, older age, injection drug use (IDU), high-risk heterosexual contact, and birth in Mexico and Central America (Espinoza et al., 2012, 2008).

In addition to late HIV diagnosis, disparities in survival after HIV diagnosis also exist. In 2010, the mortality rate for Latinos with HIV was more than 2.5 times the rate of their non-Latino white counterparts (female: 1.1 vs. 0.4 per 100 000; male: 4.6 vs. 1.8 per 100 000, respectively) (National Center for Health Statistics, 2014). Furthermore, the 3year survival rate in the US for foreign-born Latinos diagnosed with AIDS between 2001 and 2005 was 88\% (95\% confidence interval (CI) 88-89) compared with 91\% (95\% CI 90-91) for US-born Latinos (Espinoza et al., 2012). Disparities in survival after HIV diagnosis also exists among varying HIV risk groups, with Latinos with HIV attributable 
to IDU experiencing the lowest one-year (83.8\%, 95\% CI 83.6-84.0) and five-year (75.3\%, 95\% CI 75.0-75.5) survival rates when compared with Latinos with HIV attributable to all other transmission modes (Espinoza et al., 2008).

In addition to demographics and individual-level risks, neighborhood-level socioeconomic status (SES) might also influence the timing of HIV diagnosis and the length of survival among Latinos with HIV. A study of New York City’s HIV/AIDS surveillance data found that over $60 \%$ of individuals who were diagnosed late with HIV lived in neighborhoods with high levels of poverty (Hanna et al., 2008). Additionally, neighborhood-level educational attainment has been associated with late HIV diagnosis in urban areas (Trepka et al., 2014). Areas with low SES have also been associated with low HIV and AIDS survival (Hanna et al., 2008, Joy et al., 2008, McFarland et al., 2003). Furthermore, neighborhood poverty has been shown to partially account for racial/ethnic disparities in HIV/AIDS survival (Trepka et al., 2013, Arnold et al., 2009) and antiretroviral initiation (Arnold et al., 2009). Possible mechanisms to the relationship between neighborhood-level SES and health include increased psychological stress, decreased positive social networks, and fewer health and social support services (Boardman et al., 2001, Galea et al., 2003, Kirby \& Toshiko, 2005).

Neighborhood-level ethnic density (the proportion of a racial/ethnic group in a defined area) has also been linked to health outcomes (Inagame et al., 2006, Schneider et al., 2008) and health care utilization (Haas et al., 2004, Gaskin et al., 2012, Kaestle \& Wiles, 2010, Quinn et al., 2009, Benjamins et al., 2004) among the general Latino population. In the US, the protective effect of ethnic density has most consistently been 
reported for Latinos (Bécares et al., 2012). Studies have shown lower all-cause mortality among the general Latino population who reside in neighborhoods with high Latino ethnic density (Bécares et al., 2012). Additional benefits of ethnic density for Latinos have been reported for heart disease (Alvarez \& Levy, 2012) and mortality (Franzini \& Spears, 2003); stroke; lung, breast and colorectal cancer (Franzini \& Spears, 2003, Eschbach et al., 2005); smoking during pregnancy (Shaw et al., 2010), infant mortality (Shaw et al., 2010, Jenny et al., 2001), preterm birth (Mason et al., 2010, Masi et al., 2007), and low birth weight (Masi et al., 2007, Peak \& Weeks, 2002); depression (Gerst et al., 2011, Sheffield \& Peek, 2009, Ostir et al., 2003); poor self-rated health (Patel et al., 2003, Shaw \& Pickett, 2011); cholesterol screening (Benjamins et al., 2004); and access to care (Haas et al., 2004). Empirical data suggest that ethnic density might work through decreased exposure to racism (Whitley et al. 2006, Becares et al., 2009) and discrimination (Whitley et al., 2006, Becares et al., 2009, Das-Munshi et al., 2010); improved social support (Das-Munshi et al., 2010, Halperin \& Nazroo 2000), social cohesion (Hong et al., 2014) and social networks (Whitley et al., 2006, Becares et al., 2009, Das-Munshi et al., 2010); and increased access to care (Benjamins et al., 2004, Haas et al., 2004) and culturally appropriate resources (Whitley et al., 2006).

Finally, the rural-urban status of a neighborhood has also been linked to health outcomes among individuals with HIV. Studies, including one among Latinos (Espinoza et al., 2012), have found lower rates of HIV testing (Ohl et al., 2011), and increased risk of late diagnosis (Espinoza et al., 2012, Trepka et al., 2014, Weis et al., 2010) and delayed HIV care (Ohl et al., 2010) among individuals residing in rural compared with urban areas. Potential mechanisms include low access to and utilization of healthcare 
services (Metsch \& McCoy, 1999), limited availability of HIV-related resources (Sutton et al., 2010), heightened HIV-related stigma, and decreased confidentiality in rural and low HIV prevalence areas (Zukoski \& Thorburn, 2009).

The overall objective of this dissertation was to estimate disparities in late HIV diagnosis and all-cause mortality among varying populations of HIV-positive Latinos, and to identify neighborhood-level predictors. Specifically, we sought to examine the role of neighborhood SES, Latino ethnic density, and rural-urban residence on late diagnosis and mortality among male vs. female Latinos, foreign- vs. US-born Latinos, and Latinos with vs. without a history of IDU. These objectives were accomplished through three separate studies. The first study aimed to: (1) examine individual and neighborhood determinants of late HIV diagnosis among Latinos and (2) compare differences in late diagnosis by gender and country of birth. The second study aimed to: (1) examine disparities in mortality risk among HIV-positive Latinos with a history of IDU compared with those without a history of IDU, and (2) compare individual- and neighborhood-level predictors of mortality for these two groups. The third and final study aimed to: (1) examine the role of neighborhood Latino ethnic density in all-cause mortality among HIV-positive Latinos, (2) compare the role of Latino ethnic density in mortality within Latinos of varying birth countries/regions, and (3) determine if Latino ethnic density ameliorates disparities within Latinos.

\section{References}

Alvarez KJ, Levy BR. Health advantages of ethnic density for African American and Mexican American elderly individuals. Am J Public Health. 2012;102(12):2240-2. 
Arnold M, Hsu L, Pipkin S, McFarland W, Rutherford GW. Race, place and AIDS: The role of socioeconomic context on racial disparities in treatment and survival in San Francisco. Soc Sci Med. 2009;69(1):121-128.

Bécares L, Nazroo JY, Stafford M. The buffering effects of ethnic density on experienced racism and health. Health Place. 2009;15(3):670-8.

Becares L, Shaw R, Nazroo J, Stafford M, Albor C, Atkin K, et. al. Ethnic density effect on physical morbidity, mortality, and health behaviors: a systematic review of the literature. Am J Public Health. 2012;102(12):e33-66.

Benjamins MR, Kirby JB, Bond Huie SA. County characteristics and racial and ethnic disparities in the use of preventive services. Prev Med. 2004;39(4):704-712.

Boardman JD, Finch BK, Ellison CG, Williams DR, Jackson JS. Neighborhood disadvantage, stress, and drug use among adults. J Health Soc Behav. 2001;42:151-165.

Centers for Disease Control and Prevention. NCHHSTP Atlas. Atlanta, GA: Centers for Disease Control and Prevention. http://gis.cdc.gov/GRASP/NCHHSTPAtlas/main.html. n.d. Retrieved Aug 2014.

Chen M, Rhodes PH, Hall HI, Kilmarx PH, Branson BM, Valleroy LA. Prevalence of undiagnosed HIV infection among persons aged $\geq 13$ years - National HIV Surveillance System, United States, 2005-2008. MMWR Morb Mortal Wkly Rep. 2012;61:sup 57-64.

Cohen MS, Chen YQ, McCauley M, et al. Prevention of HIV-1 infection with early antiretroviral therapy. N Engl J Med. 2011;365(6):493-505.

Das-Munshi J, Becares L, Dewey ME, Stanfield SA, Prince MJ. Understanding the effect of ethnic density on mental health: multi-level investigation of survey data from England. BMJ. 2010;341:c5367.

Eschbach K, Mahnken J, Goodwin J. Neighborhood composition and incidence of cancer among Hispanics in the United States. Cancer. 2005;103(5):1036-44.

Espinoza L, Hall HI, Selik RM, Hu X. Characteristics of HIV infection among Hispanics, United States 2003-2006. J Acquir Immune Defic Syndr. 2008;49(1):94-101.

Espinoza L, Hall HI, Hu X. Diagnoses of HIV infection among Hispanics/Latinos in 40 states and Puerto Rico, 2006-2009. J Acquir Immune Defic Syndr. 2012;60(2):205-213.

Franzini L, Spears W. Contributions of social context to inequalities in years of life lost to heart disease in Texas, USA. Soc Sci Med. 2003;57(10):1847-61. 
Galea S, Ahern J, Vlahov D. Contextual determinants of drug use risk behavior: a theoretical framework. J Urban Health. 2003;80:iii50-iii58.

Gaskin DJ, Dinwiddie GY, Chan KS, McCleary R. Residential segregation and disparities in health care utilization. Med Care Rese and Rev. 2012;69(2):158-175.

Gerst K, Miranda PY, Eschbach K, Sheffield KM, Peek MK, Markides KS. Protective neighborhoods: neighborhood proportion of Mexican Americans and depressive symptoms in very old Mexican Americans. J Am Geriatr Soc. 2011;59(2):353-8.

Haas JS, Phillips KA, Sonneborn D, McCulloch CE, Baker LC, Kaplan CP, Perez-Stable EJ, Liang SY. Variation in access to health care for different racial/ethnic groups by racial/ethnic composition of individual's county of residence. Med Care. 2004;42(7):704714.

Hall HI, Holtgrave DR, Maulsby C. HIV transmission rates from persons living with HIV who are aware and unaware of their infection. AIDS. 2012;26(7):893-896.

Halpern D, Nazroo JY. The ethnic density effect: results from a national community survey of England and Wales. Int J Soc Psychiatry. 2000;46(1):34-46.

Hanna DB, Pfeiffer MR, Torian LV, Sackoff JE. Concurrent HIV/AIDS diagnosis increases the risk of short-term HIV-related death among persons newly diagnosed with AIDS, 2002-2005. AIDS Patient Care STDS. 2008;22(1):17-28.

Hong S, Zhang W, Walton E. Neighborhoods and mental health: exploring ethnic density, poverty, and social cohesion among Asian Americans and Latinos. Soc Sci Med. 2014;111:117-24.

Inagami S, Borell LN, Wong MD, Fang J, Shapiro MF, Asch SM. Residential segregation and Latino, black and white mortality in New York City. J Urban Health. 2006;83(3):406-420.

Jenny AM, Schoendorf KC, Parker JD. The association between community context and mortality among Mexican American infants. Ethn Dis. 2001;11(4):722-31.

Joy R, Druyts EF, Brandson EK, Lima VD, Rustad CA, Zhang W, Wood E, Montaner JS, Hogg RS. Impact of neighborhood-level socioeconomic status on HIV disease progression in a universal health care setting. J Acquir Immune Defic Syndr. 2008;47:500-505.

Kaestle CE, Wiles BB. Targeting high-risk neighborhoods for tobacco prevention education in schools. Am J Public Health. 2010;100(9):1708-1713.

Kirby JB, Toshiko K. Neighborhood socioeconomic disadvantage and access to health care. J Health Soc Behav. 2005;46:15-31. 
Masi CM, Hawkley LC, Piotrowski ZH, Pickett KE. Neighborhood economic disadvantage, violent crime, group density, and pregnancy outcomes in a diverse, urban population. Soc Sci Med. 2007;65(12):2440-57.

Mason SM, Kaufman JS, Daniels JL, Emch ME, Hogan VK, Savitz DA. Neighborhood ethnic density and preterm birth across seven ethnic groups in New York City. Health Place. 2010;17:280-88.

McFarland W, Chen S, Hsu L, Schwarcz S, Katz M. Low socioeconomic status is associated with a higher rate of death in the era of highly active antiretroviral therapy, San Francisco. J Acquir Immune Defic Syndr. 2003;33:96-103.

Metsch LR, McCoy CB. Drug treatment experience: rural and urban comparison. Subst Use Misuse. 1999;34:763-784.

Ohl M, Tate J, Duggal M, et al. Rural residence is associated with delayed care entry and increased mortality among veterans with human immunodeficiency virus infection. Med Care 2010;48:1064-1070.

Ohl ME, Perencevich E. Frequency of human immunodeficiency virus (HIV) testing in urban vs. rural areas of the United States: Results from a nationally-representative sample. BMC Public Health 2011;11:681.

Ostir GV, Eschbach K, Markides KS, Goodwin JS. Neighbourhood composition and depressive symptoms among older Mexican Americans. J Epidemiol Community Health. 2003;57(12):987-92.

Patel KV, Eschbach K, Rudkin LL, Peek MK, Markides KS. Neighborhood context and self-rated health in older Mexican Americans. Ann Epidemiol. 2003;13(9):620-28.

Peak C, Weeks JR. Does community context influence reproductive outcomes of Mexican origin women in San Diego, California? J Immigr Health. 2002;4(3):125-36.

Quinn BC, Catalano RA, Felber E. The effect of community-level unemployment on preventive oral health care utilization. Health Serv Res. 2009;44(1):162-181.

Shaw RJ, Pickett KE, Wilkinson RG. Ethnic density effects on birth outcomes and maternal smoking during pregnancy in the US Linked Birth and Infant Death data set. Am J Public Health. 2010;100(4):707-13.

Shaw RJ, Pickett KE. The association between ethnic density and poor self-rated health among US black and Hispanic people. Ethn Health. 2011;16(3):225-44.

Sheffield KM, Peek MK. Neighborhood context and cognitive decline in older Mexican Americans: Results from the Hispanic Established Populations for Epidemiologic Studies of the Elderly. Am J Epidemiol, 2009;169(9):1092-101. 
Schneider E, Whitmore S, Glynn MK, Dominguez K, Mitsch A, McKenna MT. Revised surveillance case definitions for HIV infection among adults, adolescents, and children aged $<18$ months and for HIV infection and AIDS among children aged 18 months to $<13$ years --- United States, 2008. MMWR Morb Mortal Wkly Rep. 2008;57(RR10):1-8.

Sutton M, Anthony M, Vila C, McLellan-Lemal E, Weidle PJ. HIV testing and HIV/AIDS treatment services in rural counties in 10 southern states: Service provider perspectives. J Rural Health. 2010;26, 240-247.

Trepka MJ, Niyonsenga T, Maddox L, Spencer L, Lutfi K, Pavlova-McCalla E. Community poverty and trends in racial/ethnic survival disparities among people diagnosed with AIDS in Florida, 1993-2004. Am J Public Health. 2013;103(4):717-726.

Trepka MJ, Fennie KP, Sheehan DM, Lutfi K, Maddox L, Lieb S. Late HIV diagnosis: differences by rural/urban residence, Florida, 2007-2011. AIDS Patient Care STDS. 2014;28(4):188-197.

Weis KE, Liese AD, Hussey J, Gibson JJ, Duffus WA. Associations of rural residence with timing of HIV diagnosis and stage of disease at diagnosis, South Carolina 20012005. J Rural Health 2010;26:105-112.

Whitley R, Prince M, McKenzie K, Stewart R. Exploring the ethnic density effect: a qualitative study of a London electoral ward. Int J Soc Psychiatry. 2006;52(4):376-91.

Zukoski AP, Thorburn S. Experiences of stigma and discrimination among adults living with HIV in a low HIV prevalence context: A qualitative analysis. AIDS Patient Care STDS. 2009;23:267-276. 


\title{
MANUSCRIPT 1
}

Individual and neighborhood determinants of late HIV diagnosis among Latinos, Florida, 2007-2011

\begin{abstract}
Objective: To examine individual and neighborhood determinants of late HIV diagnosis by gender and birthplace among Latinos. Methods: Florida HIV surveillance for 20072011 were merged with American Community Survey data to estimate the odds of late HIV diagnosis (AIDS within 3 months of HIV diagnosis). Results: Of 5,522 HIVpositive Latinos, 26.5\% were diagnosed late. The odds ratio (OR) for late diagnosis was 1.37 times higher for males than females (95\% confidence interval [CI] 1.13-1.67). Neighborhood-level factors associated included residing in the lowest quartile of neighborhood education for females, and in the 3 highest quartiles of unemployment for males. The OR was 1.24 times higher for foreign- than US-born Latinos (95\% CI 1.081.42). Among foreign-born, residing in $2^{\text {nd }}$ and $3^{\text {rd }}$ quartiles of neighborhood unemployment, and in an area with $<25 \%$ Hispanic/Latino population were associated. Conclusion: Targeted and improved individual- and neighborhood-level testing strategies are warranted for Latinos.
\end{abstract}

Keywords: Latinos; foreign-born Latinos; human immunodeficiency virus; acquired immune deficiency syndrome; late diagnosis 
Introduction

The rate of human immunodeficiency virus (HIV) diagnoses in the United States (US) is three times higher for Latinos than for non-Latino whites (Centers for Disease Control and Prevention, n.d.). About 20\% of HIV-positive Latinos are not aware of their HIV status (Chen et al., 2012), and over 40\% are diagnosed with acquired immunodeficiency syndrome (AIDS) within 12 months of an HIV diagnosis (Espinoza et al., 2012). An estimated $49 \%$ of HIV transmissions in the US are from persons unaware of their HIV infection (Hall et al., 2012). Persons with undiagnosed HIV infection may continue risky sexual and drug-related behaviors, unknowingly putting others at-risk. Moreover, late HIV diagnosis and subsequent late treatment, increases the risk of poor health outcomes (Cohen et al., 2011) and doubles the risk of HIV-related mortality (Hanna et al., 2008).

Reported predictors of late HIV diagnosis among Latinos include male sex, older age (Espinoza et al., 2012, 2008), injection drug use (IDU), high-risk heterosexual contact (Espinoza et al., 2008), being born outside of the US (Espinoza et al., 2012), and Spanish-speaking (Wohl et al., 2009). A study of Latinos diagnosed with HIV in 33 states and 5 US-dependent areas found males to be $40 \%$ more likely to be diagnosed late compared with females after controlling for individual-level covariates (Espinoza et al., 2008). Furthermore, Latinos born in Mexico and Central America were over 2 times more likely to be diagnosed late with HIV compared with US-born Latinos (Espinoza et al., 2008). 
In addition to demographics, area level factors might also influence the timing of HIV diagnosis. Areas with low socioeconomic status (SES) are associated with high HIV rates (Lopez-De Fede et al., 2011, Ishida et al., 2012) and low AIDS survival (Hanna et al., 2008, McFarland et al., 2003). Neighborhood poverty has also been shown to partially account for racial/ethnic disparities in HIV/AIDS survival (Trepka et al., 2013, Arnold et al., 2009) and antiretroviral initiation (Arnold et al., 2009). Although few studies have examined the role of neighborhood factors on late HIV diagnosis (Hanna et al., 2008, Trepka et al., 2014), research suggests that residential neighborhood might predict availability and utilization of health care (Haas et al., 2004, Gaskin et al., 2012) and preventive services (Kaestle \& Wiles, 2010, Quinn et al., 2009, Benjamins et al., 2004). A study of New York City’s HIV/AIDS surveillance data found over $60 \%$ of individuals who were diagnosed late with HIV lived in neighborhoods with high levels of poverty (Hanna et al., 2008). Additionally, neighborhood-level educational attainment and physician density have been associated with late HIV diagnosis in urban areas (Trepka et al., 2014). Nevertheless, these few studies examined all HIV cases (Hanna et al., 2008) or compared rural and urban cases (Trepka et al., 2014) but did not report results for Latinos specifically. Ethnic composition of neighborhoods has also been linked to health outcomes (Becares et al., 2012, Inagami et al., 2006) and health care utilization (Haas et al., 2004, Gaskin et al., 2012, Kaestle \& Wiles, 2010, Quinn et al., 2009, Benjamins et al., 2004) among the general Latino population, but has not been examined for HIV-positive Latinos.

To date, we did not identify studies that examined the role of neighborhood socioeconomic status and ethnic composition on late HIV diagnosis among Latinos. 
Therefore, the objective of this study was to examine the association between individual and neighborhood characteristics with late HIV diagnosis among HIV-positive Latinos. Specifically, we aimed to (1) examine individual and neighborhood determinants of late HIV diagnosis among Latinos and (2) compare differences in the context of gender and country of birth.

\section{Methods}

\section{Study population}

De-identified HIV surveillance data were obtained from the Florida Department of Health Enhanced HIV/AIDS Reporting System (eHARS). Latinos, ages 13 and over, who met the Centers for Disease Control and Prevention (CDC) case definition for HIV (Schneider et al., 2008) between 2007 and 2011 were included. Cases with missing or invalid data for zip code at time of HIV diagnosis, and cases diagnosed in a correctional facility were excluded.

Individual- and neighborhood-level variables

The following individual-level variables were extracted from eHARS: year of HIV diagnosis, sex at birth; age at HIV diagnosis; HIV transmission mode; birth country; HIV-to-AIDS interval in months (if case progressed to AIDS); residential zip code at time of HIV diagnosis; and whether the case was diagnosed at a correctional facility. Late HIV diagnosis was defined as AIDS diagnosis within 3 months of HIV diagnosis. A 3month time period was chosen based on the National HIV/AIDS Strategy goal to link individuals to care within 3 months of an HIV diagnosis (Centers for Disease Control and 
Prevention, 2013) and to allow for comparison to a recent CDC study using HIV surveillance data (Centers for Disease Control and Prevention, 2011). Latinos were classified as US-born if they were born in any of the 50 states, District of Columbia, Puerto Rico, or any US dependent area for the stratified analysis. The variable "birthplace” was a further categorization of place of birth and included: US (excluding Puerto Rico), Puerto Rico, Cuba, Mexico, Central America, South America, and other. The 2011 American Community Survey/Census Bureau Hispanic origin classification was used to define the Central and South America categories (American Community Survey, 2011a).

Neighborhood-level variables were obtained from the 2007-2011 American Community Survey (ACS) (American Community Survey, 2011b). Zip codes were matched to a corresponding zip code tabulation area (ZCTA). ZCTAs are generalized areal representations of zip code service areas used by the ACS to tabulate summary statistics (United States Census Bureau, n.d.). Extracted ZCTA-level characteristics were: percent of the population living below the poverty line; percent of the population aged 16 years and older who are unemployed; percent of the population aged 18 years and older that was a high school graduate; and percent of the population who identified as Hispanic or Latino. Neighborhood-level SES variables (poverty, unemployment, and education), were divided into quartiles of the Florida population. Based on previous research (Alvarez \& Levy, 2012, Shaw et al., 2010), the percent of Hispanics/Latinos in the ZCTA was divided into 3 categories: $<25 \%, 25-49 \%$, and $\geq 50 \%$. Version 2.0 of Rural-Urban Commuting Area (RUCA) codes, developed by the University of Washington WWAMI Rural Research Center (WWAMI Rural Health Research Center, n.d.), were used to 
divide ZCTAs into rural or urban status. Categorization $\mathrm{C}$ was used to address small numbers of HIV cases in isolated small rural towns.

Analysis

Latinos were categorized as having a late HIV diagnosis or not. Timing of HIV diagnosis was compared across individual- and neighborhood-level variables using chisquare tests for categorical variables (table 1). The bivariate analyses were repeated comparing Latinos by gender and US- vs. foreign-born status. An $\alpha \leq 0.25$ was used to determine which individual- and neighborhood-level variables to include in the multilevel logistic regression models (Hosmer \& Lemeshow, 2000). Multilevel (level 1: individual; level 2: ZCTA) modeling was used to account for correlation among cases living in the same ZCTA. SAS GLIMMIX procedure was used to calculate crude, individual-level adjusted and individual and neighborhood-level adjusted ratios (ORs), treating ZCTA as a random effect. Models were stratified by gender (table 2) and US- vs. foreign-born status (table 3). SAS software, version 9.3 (SAS Institute, Cary, NC 2002) was used to conduct all analyses. The Florida International University and Florida Department of Health Institutional Review Boards approved this study.

\section{Results}

In Florida, there were 5,522 Latinos diagnosed with HIV between 2007-2011 who met the inclusion criteria. Of these, 1,462 (26.5\%) were diagnosed with AIDS within 3 months of an HIV diagnosis (table 1). The proportion of females (28.9\%) and males 
(26.0\%) diagnosed late with HIV was similar ( $\mathrm{p}=0.0657$ ). Late HIV diagnosis was more common among foreign- (28.5\%) compared with US-born (23.7\%) Latinos $(\mathrm{p}<0.0001)$.

\section{Male vs. female Latinos}

After adjusting for individual- and neighborhood-level factors, the odds of late diagnosis was 1.37 times higher for males compared with females (95\% confidence interval [CI] 1.13-1.67) (not in table). In the multivariable analyses, being diagnosed with HIV at 20 years of age or older compared with 13-19 and being born in Mexico or Central America was independently associated with higher odds of late diagnosis in both females and males (table 2). For females only, residing in the lowest quartile of neighborhood high school graduates compared with the highest quartile was additionally associated with higher odds. For males, residing in the 3 highest quartiles of neighborhood unemployment compared with the lowest quartile, and in the third highest quartile of high school graduates compared with the highest quartile was additionally associated. A mode of transmission of men who have sex with men (MSM) compared with heterosexual transmission was associated with lower odds of late diagnosis for males.

US vs. foreign-born Latinos

After adjusting for significant individual- and neighborhood-level factors, the odds of late diagnosis was 1.24 times higher for foreign- compared with US-born Latinos (95\% CI 1.08-1.42) (not in table). In the multivariate analyses, being 20 years or older at time of diagnosis compared with 13-19 years of age was associated with higher odds of late HIV diagnosis for both US-born and foreign-born Latinos (table 3). Reporting the 
HIV transmission mode of MSM compared with heterosexual sex was associated with lower odds for both groups. For foreign-born Latinos only, being male compared with female, and residing in the second and third highest quartiles of neighborhood unemployment compared with the lowest quartile, the third highest quartile of high school graduates compared with the highest quartile, and $<25 \%$ compared with $\geq 50 \%$ Hispanic/Latino population was associated with higher odds of late HIV diagnosis.

\section{Discussion}

Our study found $26.5 \%$ of Latinos diagnosed with AIDS within 3 months of an HIV diagnosis between 2007-2011 in Florida; similar to national rates for 2011 (27.4\%) (Centers for Disease Control and Prevention, 2013). Older age was a consistent determinant of late HIV diagnosis among both sexes and among US- and foreign-born Latinos. Latinos born in Mexico and Central America were significantly more likely to be diagnosed late compared with US-born Latinos. Low neighborhood educational attainment increased the odds of late diagnoses for females. Higher neighborhood unemployment put males at-risk only. Neighborhood characteristics did not affect Latinos born in the US. However, neighborhood unemployment, education, and percent Hispanic/Latino were associated with late diagnosis for foreign-born Latinos.

Older age has been associated with late HIV diagnosis among Latinos in several studies (Espinoza et al., 2012, 2008). Disease progression has been reported to occur at a faster rate in older individuals (Langford et al., 2007). Our data did not allow us to differentiate between old and recent HIV infections. Therefore, it is possible that we overestimated the proportion diagnosed late for older Latinos. It is important for future 
research to differentiate between accelerated progression of HIV and late diagnosis among this group to determine if strategies to improve HIV testing are needed. Nevertheless, the rate of new HIV diagnoses among older Latinos is high (19.5 vs. 3.9 per 100,000 in non-Latino whites per year) (Linley et al., 2012), and over 80\% of Latinos over the age of 48 have never been tested for HIV (Lopez-Quintero et al., 2000).

The finding that males are at increased odds of late HIV diagnosis is consistent with national results (Espinoza et al., 2012, 2008, 2007). A study of Latinos in 33 states and 5 US-dependent areas found the adjusted odds of late diagnosis was 1.4 times higher for males compared with females (95\% CI 1.2-1.6) (Espinoza et al., 2008); consistent with our findings (aOR 1.37, 95\% CI 1.13-1.67). This might reflect the low HIV testing rates among male Latinos compared with their female counterparts (Lopez-Quintero et al., 2005). Our result of foreign- vs. US-born Latinos (aOR 1.24, 95\% CI 1.08-1.42) is also consistent with a national study (adjusted prevalence ratio 1.2, 95\% CI 1.16-1.24) (Espinoza et al., 2012). However, a separate study in Los Angeles found no difference between foreign- and US-born Latinos (Wohl et al., 2009) suggesting that Latinos, or their circumstance, exposure, or life experiences, in Florida differ from those in California or that HIV testing strategies in Los Angeles are reaching both groups equally.

Our study found $41 \%$ of HIV-positive Latinos born in Mexico and 37\% of those born in Central America diagnosed late. Moreover, they had over twice the odds of late diagnoses compared with US-born Latinos. These results are similar to aggregate results for the US (Mexico aOR 2.2, 95\% CI 1.8-2.5; Central America aOR 2.5, 95\% CI 2.0-3.2) (Espinoza et al., 2008). Among Latinos in the US, Mexicans are also more likely to 
report never having been tested for HIV compared to Puerto Ricans, Central and South Americans, and other Latinos (Lopez-Quintero et al., 2005). The lack of HIV testing and high odds of late diagnosis are concerning as it is estimated that the annual number of HIV diagnoses is increasing between 9 and 25\% for Latinos born in Mexico and Central America (Espinoza et al., 2008). It is important to note that national results for late HIV diagnosis for Latinos born in Mexico (Espinoza et al., 2008) approximate our results for males only (aOR 2.21, 95\% CI 1.68-2.91). We found a larger disparity between females born in Mexico and females born in the US (aOR 3.57, 95\% CI 1.62-7.90). This suggests that females born in Mexico might experience added barriers to testing.

Females residing in the lowest quartile of neighborhood education had higher odds of late diagnosis compared to those residing in the highest quartile of education. Low individual-level educational attainment has been associated with no prior HIV testing among Latinos in the US (Lopez-Quintero et al., 2005). Furthermore, neighborhood-level education has been associated with late diagnosis in urban areas in Florida (Trepka et al., 2014). A population-based study in Kenya reported that higher neighborhood educational attainment was protective against HIV risk and a stronger predictor for risk than education at the individual and household-level (Ishida et al., 2012). The authors suggest that neighborhood-level education impacts the transmission of HIV knowledge among neighbors (Ishida et al., 2012). In our study, males who resided in the three highest quartiles of unemployment had higher odds of late diagnoses compared with those who resided in the lowest quartile of unemployment. A study of National Health Interview Survey data found no difference in HIV testing between Latinos who were unemployed compared with those who were employed (Lopez- 
Quintero et al., 2005). This suggests that a structural, rather than an individual-level mechanism may play a role.

Our study suggests that neighborhood characteristics only affect foreign-born Latinos. Neighborhood-level factors examined in this study did not predict late diagnosis for US-born Latinos. For foreign-born Latinos, living in the $2^{\text {nd }}$ and $3^{\text {rd }}$ highest quartiles of unemployment increased the odds of late diagnosis. Although foreign-born Latinos (1.8\%) are less likely to be unemployed compared to US-born Latinos (2.8\%), they are more likely to be uninsured (49.3 vs. 18\%, respectively) (Brown \& Patten, 2014a). This might reflect work in industries that are less likely to offer employer-based health insurance (Brown \& Patten, 2014b). The association between the $4^{\text {th }}$ and highest quartile of unemployment and late diagnosis was not statistically significant among foreign-born Latinos but the estimate was in the same direction and general magnitude to the third quartile of unemployment. Residing in a neighborhood with a low Latino ethnic density (i.e. less than 25\% Hispanic/Latino population) also increased the odds of late HIV diagnosis for foreign-born Latinos. A previous study by Gaskin et al. found Latinos more likely to have an office-based physician visit when they resided in predominately Latino communities than non-Latino whites and blacks in Latino areas (Gaskin et al., 2012). The authors suggested that this unexpected protective effect may be due to Latinos in predominantly Latino areas having better access to social networks and a higher rate of language-concordant patient/provider interactions. This is consistent with a previous study that found Spanish language to be strongly linked to late HIV diagnosis for Latinos (Wohl et al., 2009). Communities with a larger proportion of Latinos might specifically 
target HIV testing strategies, outreach, and other resources to Latinos, including the provision of information in Spanish (Whitley et al., 2006, Lee, 2009, White et al., 2012).

Finally, our result that rural residence is not associated with late diagnosis among Latinos is inconsistent with previous findings. Espinoza et al., found higher odds of late diagnosis among Latinos residing in rural vs. urban areas (Espinoza et al., 2012). However, this previous study did not account for neighborhood-level socioeconomic status or ethnic composition. While we found rural residence to be associated with late diagnosis in the crude regression analyses for males and foreign-born Latinos, this effect disappeared after adjusting for covariates. It is possible that the crude association between rural residence and late diagnosis is mainly due to individual-level or neighborhood characteristics examined in this study or that the few number of rural cases ( $\mathrm{n}=88$ ) limited our power for the more complex, multivariate, regression models.

Additionally, rural areas in Florida might be in relative close proximity to urban centers compared to other states. Similarly, neighborhood-level poverty was also not associated with late diagnosis in our study. These findings are consistent with a study examining rural and urban differences in late diagnosis among all HIV-positive Latinos in Florida (Trepka et al., 2014), and a study reporting no difference in HIV testing between Latinos in the general US population living below the poverty line compared with those living at or above the poverty line (Lopez-Quintero et al., 2005).

This study is not without limitations. First, our definition of late HIV diagnosis differed from previous studies examining Latinos. These studies used a 12-month HIVto-AIDS interval (Espinoza et al., 2012, 2008). Therefore, we were unable to compare the 
proportion of Latinos diagnosed late in Florida with national rates for specific Latino ethnic subgroups. However, it was important to match our definition to the CDC national report (Centers for Disease Control and Prevention, 2013) and measure late diagnosis in a manner useful for determining our progress with the HIV/AIDS national strategy.

Second, our dataset did not contain individual-level socioeconomic status, length of time in the US for foreign-born Latinos, language of preference, health insurance status, level of acculturation, or information regarding perceived risk for HIV (Lopez-Quintero et al., 2005). These variables may be important predictors of late diagnosis. Third, we are unsure of the length of time that cases were exposed to the ZCTA of residence reported at the time of diagnosis. Fourth, we were only able to study neighborhood factors at the ZCTA-level, as it was the smallest geographic unit available in the dataset. Finally, our study may not be generalizable to the predominantly Mexican foreign-born Latino population in the US as our sample of foreign-born Latinos was largely Cuban. Despite this difference, our results appear to parallel several national studies suggesting a higher degree of generalizability than expected.

The findings of this study suggest that Latinos who are older, male, and born in Mexico and Central America are not fully benefiting from existing HIV testing programs. Enhanced strategies that target specific barriers for these groups are warranted. Females in areas with low educational attainment and males in areas with high unemployment also appear to be experiencing added barriers. Finally, further outreach might be needed to ensure that Latinos who are isolated from their ethnic group know where they can get tested and feel comfortable doing so in predominantly non-Latino areas. Further research is needed to understand why neighborhood factors appear to affect foreign-born Latinos 
only and to identify mechanisms for the relationship between place and late HIV diagnosis.

\section{Conclusions}

To our knowledge this is the first study to identify neighborhood-level predictors of late HIV diagnosis for Latinos that go beyond rural/urban differences. Our findings suggest that HIV testing campaigns in areas with low educational attainment are not reaching Latino women and that areas with high unemployment might need to focus on decreasing testing barriers for men. Additionally, foreign-born Latinos in predominantly non-Latino areas appear to be at greater risk of late HIV diagnosis.

\section{References}

Alvarez KJ, Levy BR. Health advantages of ethnic density for African American and Mexican American elderly individuals. Am J Public Health. 2012;102(12):2240-2242.

American Community Survey. American Community Survey and Puerto Rico Community Survey 2011 code list. Washington, DC: American Community Survey United States Census Bureau.

http://www.census.gov/acs/www/Downloads/data_documentation/CodeLists/2011_ACS_ Code_Lists.pdf. 2011a. Retrieved Sept 2014.

American Community Survey. 2011 American Community Survey 5-year estimates. Washington, DC: American Community Survey United States Census Bureau. http://factfinder2.census.gov. 2011b. Retrieved Jan 2014.

Arnold M, Hsu L, Pipkin S, McFarland W, Rutherford GW. Race, place and AIDS: The role of socioeconomic context on racial disparities in treatment and survival in San Francisco. Soc Sci Med. 2009;69(1):121-128.

Becares L, Shaw R, Nazroo J, Stafford M, Albor C, Atkin K, et. al. Ethnic density effect on physical morbidity, mortality, and health behaviors: a systematic review of the literature. Am J Public Health. 2012;102(12):e33-66.

Benjamins MR, Kirby JB, Bond Huie SA. County characteristics and racial and ethnic disparities in the use of preventive services. Prev Med. 2004;39(4):704-712. 
Brown A, Patten E. Statistical portrait of Hispanics in the United States, 2012. Washington, DC: Pew Research. http://www.pewhispanic.org/2014/04/29/statisticalportrait-of-hispanics-in-the-united-states-2012/\#persons-without-health-insurance-byage-race-and-ethnicity-2012. 2014a. Retrieved Sept 2014.

Brown A, Patten E. Statistical portrait of the foreign-born population in the United States, 2012. Washington, DC: Pew Research. http://www.pewhispanic.org/2014/04/29/statistical-portrait-of-the-foreign-bornpopulation-in-the-united-states-2012/. 2014b. Retrieved Sept 2014.

Centers for Disease Control and Prevention. NCHHSTP Atlas. Atlanta, GA: Centers for Disease Control and Prevention. http://gis.cdc.gov/GRASP/NCHHSTPAtlas/main.html. n.d. Retrieved Aug 2014.

Centers for Disease Control and Prevention. High-impact HIV prevention CDC's approach to reducing HIV infection in the United States. Atlanta, GA: US Department of Health and Human Services, Centers for Disease Control and Prevention. http://www.cdc.gov/hiv/pdf/policies_NHPC_Booklet.pdf. 2011. Retrieved Sept 2014.

Centers for Disease Control and Prevention. Monitoring selected national HIV prevention and care objectives by using HIV surveillance data-United States and 6 US dependent areas-2011. HIV Surveillance Report, 2013. Vol.18 (No. 5). Atlanta, GA: US Department of Health and Human Services, Centers for Disease Control and Prevention. http://www.cdc.gov/hiv/pdf/2011_monitoring_hiv_indicators_hssr_final.pdf. 2013. Retrieved Sept 2014.

Chen M, Rhodes PH, Hall HI, Kilmarx PH, Branson BM, Valleroy LA. Prevalence of undiagnosed HIV infection among persons aged $\geq 13$ years - National HIV Surveillance System, United States, 2005-2008. MMWR Morb Mortal Wkly Rep. 2012;61:sup 57-64.

Cohen MS, Chen YQ, McCauley M, et al. Prevention of HIV-1 infection with early antiretroviral therapy. N Engl J Med. 2011;365(6):493-505.

Espinoza L, Hall HI, Hardnett F, Selik RM, Ling Q, Lee M. Characteristics of persons with heterosexually acquired HIV infection, United States 1999-2004. Am J Public Health. 2007;97(1):144-149.

Espinoza L, Hall HI, Selik RM, Hu X. Characteristics of HIV infection among Hispanics, United States 2003-2006. J Acquir Immune Defic Syndr. 2008;49(1):94-101.

Espinoza L, Hall HI, Hu X. Diagnoses of HIV infection among Hispanics/Latinos in 40 states and Puerto Rico, 2006-2009. J Acquir Immune Defic Syndr. 2012;60(2):205-213.

Gaskin DJ, Dinwiddie GY, Chan KS, McCleary R. Residential segregation and disparities in health care utilization. Med Care Rese and Rev. 2012;69(2):158-175. 
Hall HI, Holtgrave DR, Maulsby C. HIV transmission rates from persons living with HIV who are aware and unaware of their infection. AIDS. 2012;26(7):893-896.

Hanna DB, Pfeiffer MR, Torian LV, Sackoff JE. Concurrent HIV/AIDS diagnosis increases the risk of short-term HIV-related death among persons newly diagnosed with AIDS, 2002-2005. AIDS Patient Care STDS. 2008;22(1):17-28.

Haas JS, Phillips KA, Sonneborn D, McCulloch CE, Baker LC, Kaplan CP, Perez-Stable EJ, Liang SY. Variation in access to health care for different racial/ethnic groups by racial/ethnic composition of individual's county of residence. Med Care. 2004;42(7):704714.

Hosmer DW, Lemeshow S. Applied Logistic Regression. 2nd edition. New York, NY: John Wiley and Sons, Inc; 2000.

Inagami S, Borell LN, Wong MD, Fang J, Shapiro MF, Asch SM. Residential segregation and Latino, black and white mortality in New York City. J Urban Health. 2006;83(3):406-420.

Ishida K, Arnold M, Stupp P, Kizito P, Ichwara J. Exploring the connections between HIV serostatus and individual, household, and community socioeconomic resources: Evidence from two population-based surveys in Kenya. Soc Sci Med. 2012;74(2):185195.

Kaestle CE, Wiles BB. Targeting high-risk neighborhoods for tobacco prevention education in schools. Am J Public Health. 2010;100(9):1708-1713.

Langford SE, Anaworanich J, Cooper DA. Predictors of disease progression in HIV infection: a review. AIDS Res Ther. 2007;4(11).

Lee MA. Neighborhood residential segregation and mental health: a multilevel analysis on Hispanic Americans in Chicago. Soc Sci Med. 2009;68:1975-84.

Linley L, Prejean J, An Q, Chen M, Hall HI. Racial/ethnic disparities in HIV diagnoses among persons aged 50 years and older in 37 US states, 2005-2008. Am J Public Health. 2012;102(8):1527-1534.

Lopez-De Fede A, Stewart J, Hardin J, Mayfield-Smith K, Sudduth D. Spatial visualization of multivariate datasets: an analysis of STD and HIV/AIDS diagnosis rates and socioeconomic context using ring maps. Public Health Rep. 2011;126(3):115-126.

Lopez-Quintero C, Shtarkshall R, Neumark YD. Barriers to HIV-testing among Hispanics in the United States: analysis of the National Health Interview Survey, 2000. AIDS Patient Care STDS. 2005;19(10):672-83. 
McFarland W, Chen S, Hsu L, Schwarcz S, Katz M. Low socioeconomic status is associated with a higher rate of death in the era of highly active antiretroviral therapy, San Francisco. J Acquir Immune Defic Syndr. 2003;33(1):96-103.

Quinn BC, Catalano RA, Felber E. The effect of community-level unemployment on preventive oral health care utilization. Health Serv Res. 2009;44(1):162-181.

Shaw RJ, Pickett KE, Wilkinson RG. Ethnic density effects on birth outcomes and maternal smoking during pregnancy in the US Linked Birth and Infant Death data set. Am J Public Health. 2010;100(4):707-713.

Schneider E, Whitmore S, Glynn MK, Dominguez K, Mitsch A, McKenna MT. Revised surveillance case definitions for HIV infection among adults, adolescents, and children aged $<18$ months and for HIV infection and AIDS among children aged 18 months to $<13$ years --- United States, 2008. MMWR Morb Mortal Wkly Rep. 2008;57(RR10):1-8.

Trepka MJ, Niyonsenga T, Maddox L, Spencer L, Lutfi K, Pavlova-McCalla E. Community poverty and trends in racial/ethnic survival disparities among people diagnosed with AIDS in Florida, 1993-2004. Am J Public Health. 2013;103(4):717-726.

Trepka MJ, Fennie KP, Sheehan DM, Lutfi K, Maddox L, Lieb S. Late HIV diagnosis: differences by rural/urban residence, Florida, 2007-2011. AIDS Patient Care STDS. 2014;28(4):188-197.

United States Census Bureau. Geography: ZIP Code Tabulation Areas (ZCTAs). Washington, DC: United States Census

Bureau. http://www.census.gov/geo/reference/zctas.html. Retrieved April 2013.

White K, Haas JS, Williams DR. Elucidating the role of place in health care disparities: the example of racial/ethnic residential segregation. Health Serv Res. 2012;47(3):127899.

Whitley R, Prince M, McKenzie K, Stewart R. Exploring the ethnic density effect: a qualitative study of a London electoral ward. Int J Soc Psychiatry. 2006;52(4):376-91.

Wohl AR, Tejero J, Frye DM. Factors associated with late HIV testing for Latinos diagnosed with AIDS in Los Angeles. AIDS Care. 2009;21(9):1203-1210.

WWAMI Rural Health Research Center. Rural Urban Commuting Areas (RUCA). Seattle, WA: WWAMI Rural Health Research Center. http://depts.washington.edu/uwruca/. Retrieved Sept 2014. 
Tables and figures

TABLE 1- Characteristics of Latinos with late HIV diagnosis (AIDS diagnosis within 3 months of HIV diagnosis) vs. those without late diagnosis (no AIDS diagnosis within 3 months of HIV diagnosis), Florida, 2007-2011

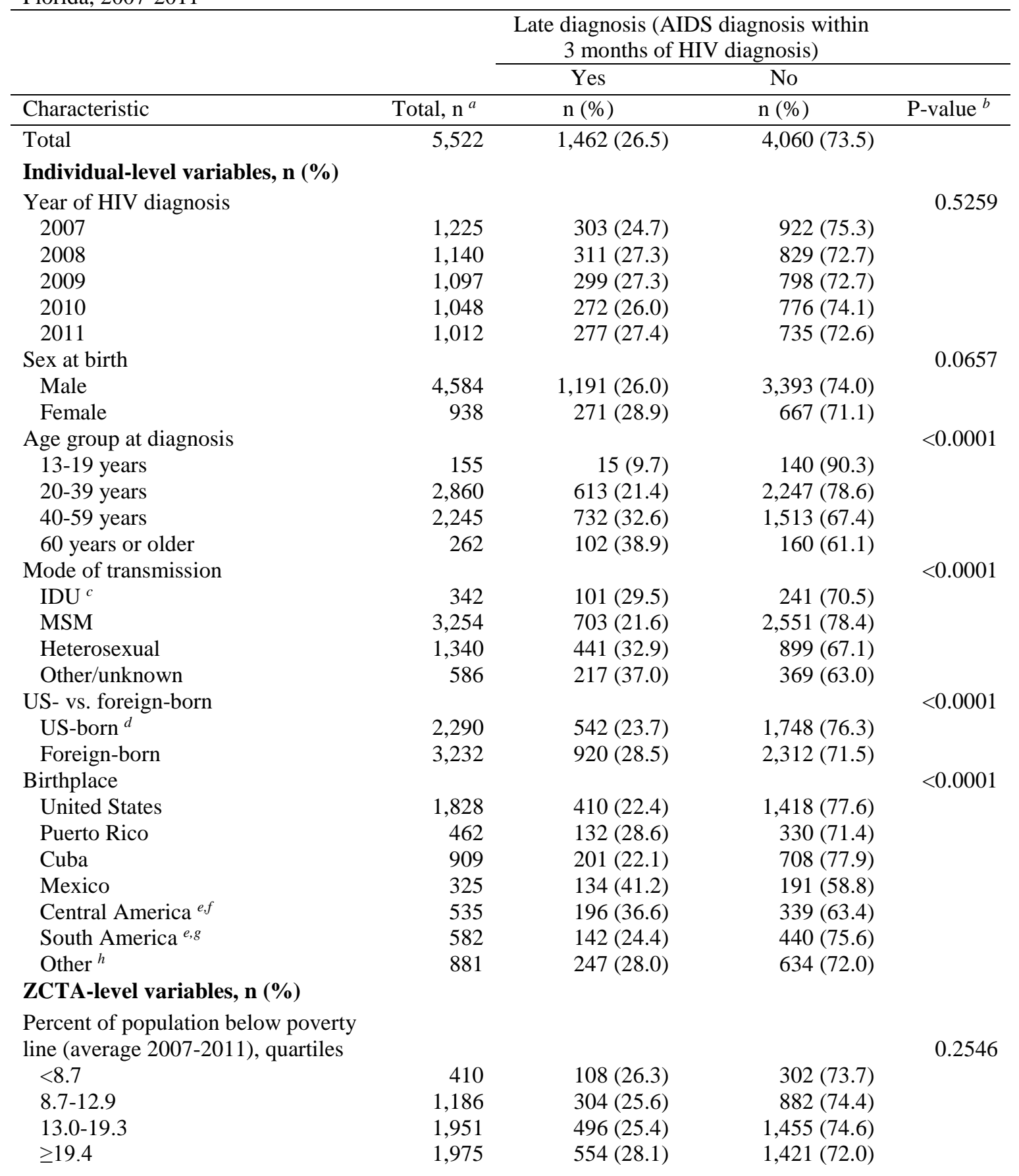


Percent of population 16 and older who is unemployed (average 2007-

2011), quartiles

$$
<4.2
$$

4.2-5.5

5.6-7.2

$\geq 7.3$

Percent of population 18 years and

older that is a high school graduate

(average 2007-2011), quartiles

$$
\geq 92.1
$$

86.9-92.0

80.4-86.8

$<80.4$

Percent of population who identified themselves as Hispanic/Latino

$\begin{array}{rl}940 & 202(21.5) \\ 1,041 & 278(26.7) \\ 1,447 & 389(26.9) \\ 2,094 & 593(28.3)\end{array}$

$\begin{array}{rl}514 & 111(21.6) \\ 1,031 & 292(28.3) \\ 1,657 & 409(24.7) \\ 2,320 & 650(28.0)\end{array}$

RUCA classification ${ }^{i}$

$738(78.5)$

763 (73.3)

1,058 (73.1)

1,501 (71.7)

0.0034

403 (78.4)

$739(71.7)$

$1,248(75.3)$

$1,670(72.0)$

0.0012

Urban

US, United States; ZCTA, zip code tabulation area; IDU, injection drug use; MSM, male to male sexual contact; RUCA, Rural-Urban Commuting Area. Percentage may not add up to 100 due to rounding.

${ }^{a}$ Excludes cases diagnosed in a correctional facility, missing residential zip code at time of HIV diagnosis, or diagnosed under the age of 13.

${ }^{b} \mathrm{P}$-value from chi-square tests.

${ }^{c}$ Includes cases reported as both IDU and MSM/IDU.

${ }^{d}$ Category includes cases born in any of the 50 states, District of Columbia, or any US dependency.

${ }^{e}$ Category defined based on the 2011 American Community Survey/Census Bureau Hispanic origin classification.

${ }^{r}$ Includes cases born in the following countries: Costa Rica, El Salvador, Guatemala, Honduras, Nicaragua, and Panama.

${ }^{g}$ Includes cases born in the following countries: Argentina, Bolivia, Chile, Colombia, Ecuador, Paraguay, Peru, Uruguay, and Venezuela.

${ }^{h}$ Includes cases identified as "Hispanic/Latino" and born in countries other than the United States, Puerto Rico, Mexico, Cuba, Central American and South America with the exception of Brazil. This category includes cases born in Brazil $(n=112)$ and the Dominican Republic $(n=94)$.

${ }^{i}$ Classified as rural or urban based on categorization $\mathrm{C}$ from the Rural-Urban Commuting Area (RUCA) data codes developed by the University of Washington WWAMI Rural Research Center. 
TABLE 2- Odds ratios and 95\% confidence intervals for late HIV diagnosis (AIDS diagnosis within 3 month of HIV diagnosis) for Latinos reported with HIV by gender, Florida, 2007-2011

\begin{tabular}{|c|c|c|c|c|c|c|}
\hline & \multicolumn{3}{|l|}{ Females } & \multicolumn{3}{|l|}{ Males } \\
\hline & $\begin{array}{l}\text { Crude OR } \\
(95 \% \text { CI })\end{array}$ & $\begin{array}{l}\mathrm{aOR}^{a} \\
(95 \% \mathrm{CI})\end{array}$ & $\begin{array}{l}\mathrm{aOR}^{b} \\
(95 \% \mathrm{CI})\end{array}$ & $\begin{array}{l}\begin{array}{l}\text { Crude OR } \\
(95 \% \text { CI })\end{array} \\
\end{array}$ & $\begin{array}{l}\mathrm{aOR}^{a} \\
(95 \% \mathrm{CI})\end{array}$ & $\begin{array}{l}\mathrm{aOR}^{b} \\
(95 \% \mathrm{CI})\end{array}$ \\
\hline \multicolumn{7}{|l|}{$\begin{array}{l}\text { Individual-level } \\
\text { variables } \\
\text { Age group at }\end{array}$} \\
\hline 13-19 years & Referent & Referent & Referent & Referent & Referent & Referent \\
\hline 20-39 years & $4.29(1.30-14.18)$ & $4.18(1.25-14.03)$ & $4.50(1.33-15.24)$ & $2.21(1.20-4.05)$ & $2.05(1.11-3.79)$ & 2.12 (1.14-3.93) \\
\hline 40-59 years & $6.60(2.00-21.73)$ & $6.76(2.02-22.66)$ & $7.30(2.16-24.73)$ & $4.01(2.19-7.36)$ & $3.82(2.07-7.08)$ & $3.95(2.13-7.34)$ \\
\hline 60 years or older & $11.37(3.18-40.71)$ & $10.70(2.91-39.42)$ & $11.97(3.21-44.70)$ & $4.83(2.48-9.39)$ & $4.40(2.23-8.66)$ & 4.67 (2.36-9.24) \\
\hline \multicolumn{7}{|l|}{$\begin{array}{l}\text { Mode of } \\
\text { transmission }\end{array}$} \\
\hline Heterosexual & Referent & Referent & Referent & Referent & Referent & Referent \\
\hline $\mathrm{IDU}^{c}$ & $0.70(0.38-1.30)$ & $0.71(0.38-1.34)$ & $0.72(0.38-1.37)$ & $0.73(0.54-0.99)$ & $0.81(0.59-1.11)$ & $0.81(0.59-1.11)$ \\
\hline MSM & -- & -- & -- & $0.44(0.37-0.53)$ & $0.54(0.45-0.65)$ & $0.56(0.46-0.69)$ \\
\hline Other/unknown & $1.44(0.99-2.10)$ & $1.46(0.99-2.15)$ & $1.44(0.97-2.13)$ & $0.95(0.74-1.22)$ & $1.01(0.78-1.31)$ & $1.00(0.77-1.30)$ \\
\hline \multicolumn{7}{|l|}{ Birthplace } \\
\hline United States & Referent & Referent & Referent & Referent & Referent & Referent \\
\hline Puerto Rico & $1.90(1.19-3.03)$ & $1.56(0.96-2.53)$ & $1.58(0.96-2.58)$ & $1.26(0.96-1.64)$ & $1.05(0.79-1.38)$ & $1.04(0.79-1.37)$ \\
\hline Cuba & $1.66(0.95-2.89)$ & $1.39(0.79-2.44)$ & $1.42(0.79-2.55)$ & $0.93(0.76-1.15)$ & $0.79(0.63-0.98)$ & $0.82(0.66-1.03)$ \\
\hline Mexico & 3.30 (1.53-7.13) & $3.68(1.67-8.10)$ & 3.57 (1.62-7.90) & $2.35(1.81-3.06)$ & $2.22(1.69-2.91)$ & $2.21(1.68-2.91)$ \\
\hline Central America & 2.09 (1.33-3.29) & $1.96(1.22-3.12)$ & $2.00(1.24-3.24)$ & $1.98(1.57-2.50)$ & $1.85(1.46-2.36)$ & $1.91(1.50-2.45)$ \\
\hline South America & $1.40(0.78-2.52)$ & $1.06(0.58-1.95)$ & $1.18(0.63-2.18)$ & $1.08(0.85-1.37)$ & 1.01 (0.79-1.29) & $1.04(0.82-1.34)$ \\
\hline Other & 1.53 (1.02-2.29) & $1.22(0.80-1.85)$ & 1.24 (0.82-1.89) & $1.31(1.06-1.60)$ & $1.08(0.87-1.34)$ & 1.09 (0.88-1.35) \\
\hline $\begin{array}{l}\text { ZCTA-level } \\
\text { variables } \\
\text { Percent of } \\
\text { population below } \\
\text { poverty line } \\
\text { (average 2007- } \\
\text { 2011), quartiles }\end{array}$ & & & & & & \\
\hline$<8.7$ & Referent & $d$ & $d$ & Referent & $d$ & Referent \\
\hline
\end{tabular}


Percent of

population 16 and

older who is

unemployed

(average 2007-

2011), quartiles$$
<4.2
$$

4.2-5.5

5.6-7.2

$\geq 7.3$

Percent of

population 18 years

and older that is a

high school

graduate (average

2007-2011),

quartiles

$\geq 92.1$

86.9-92.0

80.4-86.8

$<80.4$

Percent of

population who

identified

themselves as

Hispanic/Latino $\geq 50$

$25-49$

$<25$

RUCA

classification
Referent

$1.18(0.66-2.12)$

$1.19(0.69-2.06)$

$1.16(0.69-1.96)$

\section{Referent}

$1.75(0.93-3.30)$

$1.35(0.73-2.48)$

1.68 (0.94-2.99)

\section{Referent}

$1.88(0.98-3.61)$

$1.48(0.79-2.77)$

$1.93(1.03-3.60)$
Referent

1.38 (1.08-1.76)

1.30 (1.03-1.63)

1.33 (1.05-1.69)
Referent

0.72 (0.50-1.05)

0.99 (0.71-1.39)

Referent

\section{Referent}

1.37 (1.03-1.81)

1.21 (0.93-1.59)

1.39 (1.08-1.81)

$1.30(1.02-1.66)$

1.31 (1.05-1.65)

1.46 (1.18-1.81)

$d$

Referent

1.51 (1.11-2.05)

$1.29(0.94-1.78)$

$1.40(0.99-2.00)$

\section{Referent}

$0.82(0.55-1.22)$

$1.28(0.86-1.91)$
Referent

1.17 (0.98-1.40)

1.19 (1.01-1.41)

Referent
Referent

1.14 (0.95-1.38)

$1.11(0.90-1.35)$

Referent 
ZCTA, zip code tabulation area; IDU, injection drug use; MSM, male to male sexual contact; RUCA, Rural-Urban Commuting Area; OR, odds ratio; aOR adjusted odds ratio; $\mathrm{CI}$, confidence interval.

${ }^{a}$ Adjusted for individual-level variables with $\alpha<0.25$ in bivariate analysis.

${ }^{b}$ Adjusted for individual-level variables and ZCTA-level variables with $\alpha<0.25$ in bivariate analysis.

${ }^{c}$ IDU and IDU/MSM categories have been combined to address small cell numbers.

${ }^{d}$ Variable not included in the model. 
TABLE 3- Odds ratios and 95\% confidence intervals for late HIV diagnosis (AIDS diagnosis within 3 month of HIV diagnosis) for Latinos reported with HIV by US- vs. foreign-born, Florida, 2007-2011

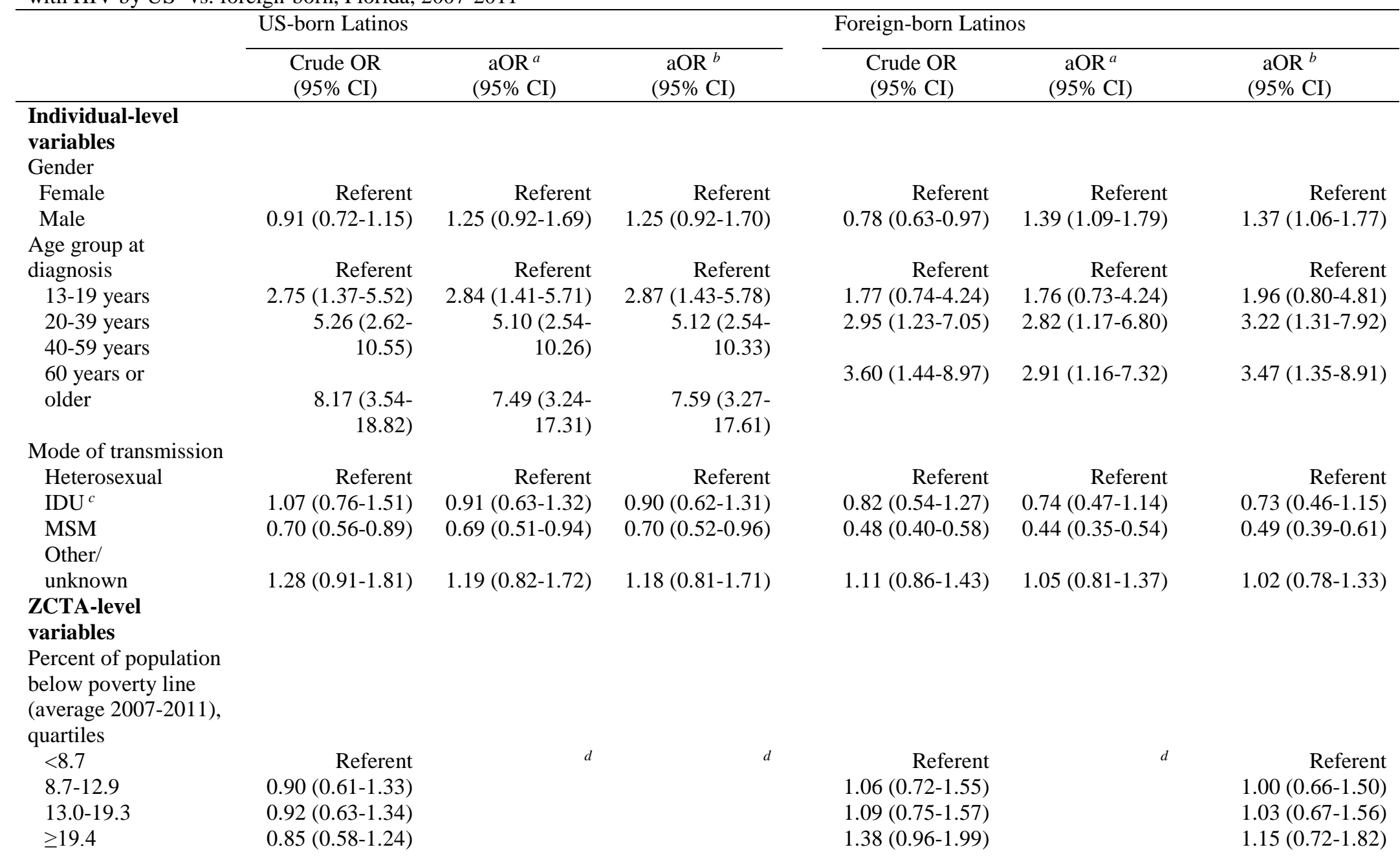


Percent of population

16 and older who is

unemployed (average 2007-2011), quartiles

$<4.2$

4.2-5.5

5.6-7.2

$\geq 7.3$

Percent of population

18 years and older that

is a high school

graduate (average

2007-2011), quartiles

$>92.1$

86.9-92.0

80.4-86.8

$<80.4$

Percent of population

who identified

themselves as

Hispanic/Latino

$\geq 50$

$25-49$

$<25$

RUCA classification

Urban

Rural

$1.18(0.80-1.74)$

$1.08(0.76-1.56)$

$1.25(0.89-1.76)$

Referent

1.42 (1.01-2.02)

$1.56(1.12-2.17)$

$1.61(1.17-2.21)$

Referent

1.45 (1.04-2.03)

1.39 (1.01-1.91)

$1.25(0.89-1.75)$

1.58 (1.09-2.30)

$1.33(0.93-1.91)$

$1.58(1.12-2.22)$

$22(0.83-1.79)$

$1.23(0.84-1.78)$

$d$

Referent

1.66 (1.11-2.48)

$1.31(0.85-2.01)$

$1.52(0.95-2.43)$

1.53 (0.75-3.12)

Referent

$1.02(0.77-1.34)$

$1.19(0.93-1.53)$

States; ZCTA, zip code tabulatio

Referent $0.99(0.75-1.29)$

$1.15(0.90-1.48)$

Referent

$1.26(0.98-1.62)$

1.30 (1.03-1.65)

d Referent

Referent

2.24 (1.24-4.06)
Referent

$1.24(0.96-1.62)$

$1.37(1.05-1.79)$

Referent 1.80 (0.98-3.32)

Area; OR, odds ratio; aOR adjusted odds ratio; CI, confidence interval.

${ }^{a}$ Adjusted for individual-level variables with $\alpha \leq 0.25$ in bivariate analysis

${ }^{b}$ Adjusted for individual-level variables and ZCTA-level variables with $\alpha \leq 0.25$ in bivariate analysis.

${ }^{c}$ IDU and IDU/MSM categories have been combined to address small cell numbers.

${ }^{d}$ Variable not included in the model. 


\title{
MANUSCRIPT 2
}

(C) Copyright 2016

Sheehan DM, Trepka MJ, Fennie KP, Prado G, Madhivanan P, Maddox L. Individual and neighborhood predictors of mortality among HIV-positive Latinos with a history of injection drug use, Florida, 2000-2011. Drug and Alcohol Dependence. 2015;154:243-50.

\begin{abstract}
Background: The objectives are to examine disparities in all-cause mortality risk among HIV-positive Latinos with injection drug use (IDU) history, and to identify individualand neighborhood-level predictors. Methods: Florida surveillance data for persons diagnosed with HIV 2000-2008 were merged with 2007-2011 administrative data from the American Community Survey. Hazard ratios (HR) were calculated using multi-level weighted Cox regression adjusting for individual and neighborhood (ZCTA-level) factors. Results: Of 10,989 HIV-positive Latinos, 10.3\% had IDU history. Latinos with IDU history were at increased mortality risk compared with Latinos without IDU history after controlling for individual and neighborhood factors (adjusted HR [aHR] 1.61, 95\% confidence interval [CI] 1.43-1.80). Factors associated with mortality for those with IDU history included: being 40-59 (aHR 6.48, 95\% CI 1.41-121.05) and $\geq 60$ years (aHR 18.75, 95\% CI 3.83-356.45) compared with 13-19 years of age; being diagnosed with AIDS within 3 months of HIV (aHR 2.31, 95\% CI 1.87-2.86); residing in an area with $\geq 50 \%$ Latinos compared with $<25 \%$ Latinos (aHR 1.56, 95\% CI 1.19-2.04); and residing
\end{abstract}


in a rural compared with an urban area at the time of diagnosis (aHR 1.73, 95\% CI 1.062.70). Race and neighborhood poverty were not predictors among those with IDU, but were among those without. Conclusion: HIV-positive Latinos with IDU history are at increased mortality risk and have unique contributing factors. Tertiary prevention strategies should target those who are older, diagnosed at later stages, and those who live in predominantly Latino and rural areas.

Keywords: Latinos; human immunodeficiency virus; mortality; injection drug use; neighborhood.

Introduction

The rate per 100,000 population of new human immunodeficiency virus (HIV) diagnoses is more than 3 times higher for Latinos than for non-Latino whites. Similarly, the rate of death among Latinos with HIV is 2 times higher than for non-Latino whites with HIV (Centers for Disease Control and Prevention, 2014). In 2011, there were 31,254 Latinos with HIV attributable to injection drug use (IDU) in the United States (US) (Centers of Disease Control and Prevention, 2014). Florida is among the top states in number of yearly HIV diagnoses and prevalent cases attributable to IDU (Centers for Disease Control and Prevention, 2014). In 2011, among HIV cases attributable to IDU in Florida, 30\% of males and 17\% of females were Latino (Florida Department of Health, 2014a).

Latinos with HIV attributable to IDU experience poor outcomes along each step of the HIV care continuum when compared with Latinos in other HIV risk groups (Gant 
et al., 2014). Thus, it is expected that Latinos with HIV attributable to IDU have lower one and five year survival rates when compared with Latinos with HIV attributable to other transmission modes (Espinoza et al., 2008). In 2013, among individuals with HIV in Florida, $86 \%$ were linked to care, $55 \%$ were retained in care, 50\% were receiving antiretroviral treatment, and 39\% were virally suppressed (Florida Department of Health, 2014b). Outcomes along the HIV care continuum for injection drug users with HIV are partially affected by the availability of HIV and drug treatment programs, as well as related services in the area. Individuals living with HIV in Florida receive HIV services through the Acquired Immune Deficiency Syndrome (AIDS) Insurance Continuation Program (est. 1989), AIDS Drug Assistance Program (est. 1987), Ryan White HIV/AIDS Program (est. 1990), Medicaid/Medicare, non-governmental organizations, and case management programs (Florida Department of Health, n.d.). Statewide substance abuse treatment in Florida is primarily provided by the Substance Abuse and Mental Health Program under the Florida Department of Children and Families (Florida Department of Children and Families, 2014).

In addition to individual-level health care-related factors, neighborhood-level (e.g. as measured by census tract, zip code, county, etc.) social factors have been linked to HIV and drug use. HIV-positive injection drug users tend to reside in clusters and concentrate in high poverty areas (Martinez et al., 2014a). Living in socioeconomically disadvantaged areas is associated with high-risk injection drug use behavior (Buchanan et al., 2003, Genereux et al., 2010), HIV seroconversion (Maas et al., 2007), and low rates of drug use cessation among injection drug users (Genberg et al., 2011, Nandi et al., 2010). Contributing to the association between neighborhood disadvantage and drug use 
behaviors are increased psychological stress, decreased positive social networks, and fewer health and social support services (Boardman et al., 2001, Galea et al., 2003, Kirby and Toshiko, 2005). Neighborhood disadvantage also is associated with increased mortality risk among the general HIV-positive population (Hanna et al., 2008, Joy et al., 2008, McFarland et al., 2003). However, no studies to date have examined the association between neighborhood socioeconomic status (SES) and mortality among HIV-positive injection drug users.

Furthermore, neighborhood-level ethnic density (i.e., neighborhood racial/ethnic composition) is associated with health outcomes. Studies have shown lower all-cause mortality among the general Latino population who reside in neighborhoods with high Latino density (Bécares et al., 2012). Based on current data, the protective effect appears to be specific to Latinos (Bécares et al., 2012). Mechanisms for the ethnic density effect include lower perceived racism (Bécares et al., 2009, Whitley et al., 2006), enhanced social support (Das-Munshi et al., 2010, Halpern and Nazroo, 2000), and increased access to culturally appropriate health care (Benjamins et al., 2004, Whitley et al., 2006). The association between ethnic density and mortality has not been examined for individuals with HIV or who use illicit drugs.

Literature suggests interactions between HIV, drug use, and neighborhood factors. However, studies have focused predominantly on non-Latino populations. Thus, our objective was to: (a) examine disparities in mortality risk among HIV-positive Latinos with a history of IDU compared with those without a history of IDU, and (b) compare individual- and neighborhood-level predictors of mortality for these two groups. 
Methods

Datasets

De-identified HIV surveillance records were obtained from the Florida Department of Health enhanced HIV/AIDS reporting system (eHARS). Cases of Latinos age $\geq 13$ who met the Centers for Disease Control and Prevention (CDC) HIV case definition (Schneider et al., 2008) during the years 2000-2008 were analyzed. Vital status was ascertained through 2011 by linkage with Florida Vital Records, the Social Security Death Master File, and the National Death Index. Cases with missing or invalid data for ZIP code at time of HIV diagnosis, and cases diagnosed in a correctional facility, were excluded. The 2007-2011 American Community Survey (ACS) was used to obtain data by ZIP code tabulation area (ZCTA) (ACS, 2014a). ZCTAs are ZIP code approximations used by the US Census Bureau to tabulate summary statistics (US Census Bureau, n.d.). Hereinafter, ZIP code/ZCTA-level data will be referred to as neighborhood-level data.

\section{Individual- and neighborhood-level variables}

The following individual-level data were extracted from eHARS: ethnicity, race, HIV diagnosis year, sex at birth, age at HIV diagnosis, HIV transmission mode, birth country, HIV-to-AIDS interval in months (if case progressed to AIDS), HIV-to-death interval in months (if individual died by December 31, 2011), residential ZIP code at time of HIV diagnosis, and whether the case was diagnosed at a correctional facility. Thirteen neighborhood-level SES indicators were extracted from the ACS (Niyonsenga et al., 2013): percent of households without access to a car, percent of households with $\geq 1$ person per room, percent of population living below the poverty line, percent of owner- 
occupied homes worth $\geq \$ 300,000$, median household income in 2011, percent of households with annual income $<\$ 15,000$, percent of households with annual income $\geq \$ 150,000$, income disparity (derived from percent of households with annual income $<\$ 10,000$ and percent of households with annual income $\geq \$ 50,000$ ), percent of population age $\geq 25$ with less than a $12^{\text {th }}$ grade education, percent of population age $\geq 25$ with a graduate professional degree, percent of households living in rented housing, percent of population age $\geq 16$ who were unemployed, and percent of population age $\geq 16$ employed in high working class occupation. We additionally extracted percent of population who identified as Hispanic or Latino from the ACS.

Individual- and neighborhood-level data were merged by matching the ZIP code at time of HIV diagnosis of each case with the ZIP code's corresponding ZCTA. Cases with IDU, or IDU plus MSM, listed as a mode of HIV transmission were categorized as having a history of IDU. Data on mode of HIV transmission were self-reported during HIV testing, reported by a health care provider, or extracted from medical chart reviews. Latinos were coded as US-born if they were born in any of the 50 states, District of Columbia, Puerto Rico, or any US dependent area. The 2011 ACS/US Census Bureau Hispanic origin classification was used to define birthplace for the Central America and South America categories (ACS, 2014b). We defined late HIV diagnosis as an AIDS diagnosis within 3 months of HIV diagnosis (CDC, 2013). Income disparity was calculated as the logarithmic of 100 times the percent of households with annual income $<\$ 10,000$ divided by the percent of households with annual income $\geq \$ 50,000$ and was used as a proxy measure of the Gini-coefficient (Niyonsenga et al., 2013; Singh and Siahpush, 2002). All neighborhood-level indicators were coded so that higher 
scoresmeant higher poverty and were standardized (Niyonsenga et al., 2013). The percent of Latinos/Hispanics in a neighborhood was divided into 3 categories: $<25 \%, 25-49 \%$, and $\geq 50 \%$ (Alvarez and Levy 2012, Shaw et al., 2010). Categorization C of Version 2.0 of the Rural-Urban Commuting Area (RUCA) codes, developed by the University of Washington WWAMI Rural Research Center (WWAMI Rural Health Research Center, n.d.), were used to categorize neighborhoods into rural or urban status.

\section{Statistical analyses}

Following the analytical methods of Niyonsenga et al. (2013), we sought to develop an SES index using the 13 ACS indicators. First, we conducted a reliability analysis. The Cronbach’s alpha for all 13 indicators was 0.9411 . We selected 7 indicators based on the correlation of the indicator with the total index (high correlation), and the Cronbach's alpha if the item was deleted (low alpha). The 7 indicators selected were: percent below poverty, median household income, percent of households with annual income $<\$ 15,000$, percent of households with annual income $\geq \$ 150,000$, income disparity, percent of population age $\geq 25$ with less than a $12^{\text {th }}$ grade education, and highclass work. The resulting Cronbach’s alpha increased (0.9564).

Second, we conducted a principal component analysis with and without varimax rotation, which revealed one factor with an eigenvalue greater than 1 (5.5632). These results are consistent with previous research (Krieger et al., 2003a, 2003b, Messer et al., 2006, Hogan and Tchernis, 2004). This factor accounted for $79.47 \%$ of the variance in the indicators. Because all the factor loadings were high (between 0.80 and 0.95), we retained all 7 indicators. The selected indicators were consistent with those chosen for the 
urban “poverty index” in Niyonsenga et al. (2013). Finally, we calculated a "poverty index” score by adding the standardized scores for the 7 variables and categorized the scores into quartiles.

Following development of the poverty index, we compared individual- and neighborhood-level characteristics by history of IDU. We used the Cochran-MantelHaenszel general association statistic for individual-level variables controlling for ZCTA, and the chi-square test for neighborhood-level variables. Third, we generated KaplanMeier survival curves for all-cause mortality by history of IDU and by neighborhood characteristics stratified by history of IDU. These analyses revealed a violation of the proportional hazard assumption. Therefore, the SAS macro PHSREG by Kohl and Heinze (2012) was used to run weighted Cox models. Multi-level (level 1: individual; level 2: neighborhood) modeling was used to account for correlation among cases living in the same neighborhood. Crude and adjusted hazard ratios and 95\% confidence intervals were calculated comparing Latinos with history of IDU with those without history of IDU. To identify predictors of mortality for each group, separate models were estimated stratifying by history of IDU. Hazard ratios were adjusted for race, HIV diagnosis year, sex, age, birthplace, late diagnosis, poverty index (hereinafter referred to as “poverty”), neighborhood-level percent Hispanic/Latino, and rural/urban status. SAS software, version 9.3 (SAS Institute, Cary, NC 2002) was used to conduct analyses. The Florida Department of Health and Florida International University institutional review boards approved our study. 
Results

Participants

Of 10,989 Latinos who were 13 years of age and older and diagnosed with HIV in Florida between 2000 and 2008, 1,126 (10.3\%) were reported as having a history of IDU (Table 1). Compared with Latinos without history of IDU, those with history of IDU were more likely to be diagnosed earlier in the epidemic (p-value $<0.0001$ ), be $40-59$ years of age (p-value $<0.0001$ ), born in the US and Puerto Rico (p-value $<0.0001$ ), and have a survival after HIV diagnosis of less than 3 years (p-value $<0.0001)$. Those with history of IDU were also more likely to live in an area in the highest quartile of neighborhood poverty (i.e., the poorest neighborhoods) (p-value <0.0029), an area with $<25 \%$ Hispanics/Latinos (p-value <0.0001), and a rural area (p-value 0.0475).

Individual and neighborhood predictors of mortality

The risk of all-cause mortality risk was two times greater for Latinos with history of IDU compared with Latinos without history of IDU (crude HR 2.00, 95\% CI 1.792.23) (Figure 1). The increased risk persisted after adjusting for individual- (aHR 1.64, 95\% CI 1.45-1.83) and individual- and neighborhood-level variables together (aHR 1.61, 95\% CI 1.43-1.80) (data not in table).

Mortality risk was higher for Latinos with history of IDU who were diagnosed in 2000-2002 compared with Latinos diagnosed in 2006-2008 (aHR 1.47, 95\% CI 1.032.13), 40-59 (aHR 6.48, 95\% CI 1.41-121.05) and $\geq 60$ years of age (aHR 18.75, 95\% CI 3.83-356.45) compared with 13-19 years of age, diagnosed late (aHR 2.31, 95\% CI 1.87- 
2.86), and who lived in a rural compared with an urban area (aHR 1.73, 95\% CI 1.062.70) (Table 2). Latinos with history of IDU who were of race other than black compared with white (aHR $0.29,95 \%$ CI $0.20-0.40$ ), lived in the $2^{\text {nd }}$ (aHR 0.44, 95\% CI 0.31-0.62) and $3^{\text {rd }}$ (aHR $0.72,95 \%$ CI $\left.0.54-0.97\right)$ quartile of poverty compared with the $1^{\text {st }}$ quartile, and in an area with $<25 \%$ Latinos compared with $\geq 50 \%$ Latinos were at decreased risk of mortality (aHR 0.64, 95\% CI 0.49-0.84).

Mortality risk was higher for Latinos without history of IDU who were black compared with Latinos who were white race (aHR 1.63, 95\% CI 1.40-1.88), diagnosed in the year 2000-2002 compared with 2006-2008 (aHR 1.85, 95\% CI 1.58-2.18), 40-59 (aHR 2.13, 95\% CI 1.42-3.36) and $\geq 60$ years of age (aHR 5.97, 95\% CI 3.92-9.58) compared with 13-19 years of age, and diagnosed late (aHR 2.27, 95\% CI 2.06-2.50) (Table 2). Mortality risk was also higher for Latinos without history of IDU who lived in the $2^{\text {nd }}$ (aHR 1.40, 95\% CI $\left.1.20-1.64\right), 3^{\text {rd }}$ (aHR 1.61, 1.39-1.87), and $4^{\text {th }}$ (aHR $1.75,95 \%$ CI 1.51-2.03) quartiles of poverty compared with the lowest quartile, and in an area with 25-49\% Latinos compared with $\geq 50 \%$ Latinos (aHR 1.29, 95\% CI 1.14-1.46).

\section{Discussion}

In our study, the adjusted mortality risk for HIV-positive Latinos with history of IDU was two times that of their non-IDU counterparts. Black race was not associated with mortality for Latinos with history of IDU but was a risk factor for Latinos without history of IDU. Age and late diagnosis were individual-level predictors for both groups. Neighborhood poverty was not consistently associated with mortality for Latinos with history of IDU, and appeared to be protective, but was a risk factor for mortality for 
Latinos without history of IDU. Residing in a low Latino ethnic density neighborhood decreased the mortality risk for Latinos with history of IDU. Finally, residing in a rural neighborhood increased the mortality risk for Latinos with history of IDU only.

HIV-positive Latinos with history of IDU were at increased risk of mortality compared with HIV-positive Latinos without history of IDU even after controlling for individual- and neighborhood-level factors. This is consistent with results from Espinoza et al. (2008) who reported lower survival rates, and with Gant et al. (2014), who reported lower proportions of linkage to and retention in care and viral suppression, among HIVpositive Latinos with history of IDU compared with Latinos without history of IDU. Our findings are inconsistent with results from a study of HIV-positive individuals in a universal health care setting that found no disparity in mortality risk between injection drug users and non-injection drug users (Joy et al., 2008). However, our study differs in that our sample included only Latinos, and included individuals with and without access to care. While we were unable to find linkage to and retention in care rates for Latino injection drug users in Florida during our study period, a study of the general HIVpositive population showed that injection drug users are 2.5 times more likely to miss healthcare visits compared with those with HIV attributable to MSM (Horberg et al., 2013) and that adherence to HIV treatment is suboptimal among injection drug users (Bouhnik et al., 2002).

Race was a risk factor for mortality among Latinos without history of IDU, but not for Latinos with history of IDU. Race for Latinos is rarely included in studies of HIVpositive Latinos, often because of limited data collection methods for race and ethnicity. 
We were unable to find a study examining racial disparities in survival among HIVpositive Latinos to compare our results. However, our findings suggest that racial disparities in HIV/AIDS survival among Latinos are wider compared with racial disparities among the general HIV-positive population (Hanna et al., 2008, Oramasionwu et al., 2009, Trepka et al., 2013b). Of note, being born in Cuba was a significant predictor of mortality for Latinos without history of IDU after controlling for all other individualand neighborhood-level predictors except for race (aHR 1.16, 95\% CI 1.01-1.34), and disappeared only after controlling for race (aHR 1.04, 95\% CI 0.90-1.20). Similarly, being born in Mexico was protective (aHR 0.72, 95\% CI 0.58-0.89), but not after controlling for race (aHR 0.90, 95\% CI 0.72-1.12).

Our findings suggest that age is additionally harmful for Latinos with history of IDU compared with Latinos without history of IDU. This effect might be biological or social in nature. Individuals diagnosed with HIV at older ages can experience faster disease progression (Langford et al., 2007, Nogueras et al., 2006). Evidence suggests that the use of drugs might also accelerate the progression of HIV to AIDS (Cole et al., 2015) by weakening the immune system, interacting with antiretroviral medication, and increasing social barriers to treatment access and adherence (Kapadia et al., 2005).

The relationship between neighborhood poverty and mortality differed for Latinos with and without history of IDU. Consistent with previous studies of the general HIVpositive population (Hanna et al., 2008, McFarland et al., 2003, Trepka et al., 2013b), neighborhood poverty was associated with increased mortality for Latinos without history of IDU. The effect was strong and persisted after controlling for individual and other 
neighborhood factors. However, our findings showed puzzling results for Latinos with history of IDU. Residing in the two middle quartiles of poverty was protective compared with the lowest quartile of poverty, but the effect disappeared for areas of highest poverty. The mechanisms through which poverty affects survival among HIV-positive Latinos (Boardman et al., 2001, Galea et al., 2003, Kirby and Toshiko, 2005) may not hold for Latinos with history of IDU. It is possible that more HIV prevention and treatment resources are allocated to higher poverty areas, as the injection drug using population in these areas is typically larger (Martinez et al., 2014a). However, the advantages of the increased targeting may not hold for areas in the highest quartile of poverty (Boardman et al., 2001, Galea et al., 2003, Kirby and Toshiko, 2005). Small numbers of Latinos with history of IDU in the lowest quartile of neighborhood poverty could have limited our ability to find an association.

Residing in an area with $<25 \%$ Latinos compared with $\geq 50 \%$ Latinos was protective for Latinos with history of IDU. This effect was not observed among Latinos without history of IDU. These findings contradict the ethnic density literature for the general Latino population, which suggests that higher, rather than lower, ethnic density provides health benefits (Eschbach et al., 2004, Inagami et al., 2006). However, past ethnic density research has been limited to all-cause mortality among the general Latino population. We speculate that high levels of HIV-related stigma in high Latino density areas are preventing HIV-positive Latinos from utilizing the enhanced social support that leads to better health (Das-Munshi et al., 2010, Halperin and Nazroo, 2000, Smith et al., 2008). HIV-related stigma is higher among Latinos compared to non-Latino whites, and among less acculturated Latinos compared to more acculturated Latinos (Rajabiun et al., 
2008). Latinos in high Latino density areas in Florida have been shown to have low acculturation levels (Schwartz et al., 2013).

Finally, our study indicates that residing in a rural compared with an urban area increases mortality risk for Latinos with history of IDU only. This effect was observed despite the relatively small number of rural residents, and the effect decreased after adjusting for individual-level and neighborhood-level factors. A previous study of HIVpositive individuals in Florida indicated no survival disparity between rural and urban residents (Trepka et al., 2013a), consistent with our findings for Latinos without history of IDU. Our finding for Latinos with history of IDU might have differed because the previous study examined individuals with AIDS of all races/ethnicities across all HIVrisk groups. The small number of rural cases did not allow us to perform subanalyses to identify associated factors. However, a study of 2,222 injection drug users and crack users in Florida found that urban participants were 2.57 times more likely to report utilizing drug treatment compared with their rural counterparts (Metsch and McCoy, 1999). Furthermore, only 4.8\% of Latino rural participants reported ever being in drug treatment. Poor access to drug treatment-coupled with limited availability of HIV-related resources (Sutton et al., 2010), heightened IDU- and HIV-related stigma, and decreased confidentiality in rural and low HIV prevalence areas-may explain rural/urban mortality disparities among Latinos with history of IDU (Zukoski and Thorburn, 2009).

Our study has limitations. First, surveillance records provide data on history of IDU to describe likely mode of HIV transmission. Therefore, while we know the drug use occurred prior to HIV diagnosis, we had no information about current IDU. Nevertheless, 
it is likely that individuals in high-poverty neighborhoods continued to use drugs, as injection cessation is lowest among those who live in neighborhoods of high deprivation (Genberg et al., 2011, Nandi et al., 2010,, Williams and Latkin, 2007). We also did not have data on history of drug abuse or use of non-IDU illicit or prescription drugs. Although the proportion of Latinos with history of IDU (10\%) was consistent with previous studies (Espinoza et al., 2012), IDU might be underreported among Latinos (Johnson and Bowman, 2003), particularly among those who are foreign-born and undocumented. Second, we were limited to using ZIP codes to define neighborhoods. A study in San Francisco found that HIV-positive injection drug users traveled within a 0.87-mile activity space daily (standard deviation [SD] 2.4 miles) and Latino injection drug users traveled 2.8 miles (SD 3.4) (Martinez et al., 2014b). Therefore, we believe most of our IDU population had the potential to be affected by ZIP code-level characteristics, particularly in urban ZCTAs that tend to be smaller in area than rural ZCTAs. Related, a high proportion of HIV-positive injection drug users have unstable housing (Aidala et al., 2007). We had relatively complete information on ZIP code at time of diagnosis but no information on ZIP code throughout the follow-up period and incomplete ZIP code at time of death. While this is a limitation, the fact that injection drug users appear to move short distances (Martinez et al., 2014b) and that ZIP codes are relatively large suggests that most injection drug users may remain in the same general neighborhood. A study of individuals who died of AIDS in Florida found that 86\% of those infected by injection drug use did not move after HIV diagnosis (Trepka et al., 2014). 
Third, researchers have suggested that less complex SES indicators (such as poverty alone) might be useful in comparing results across studies, populations, and geographic areas (Krieger et al., 2002, 2003a). Although we used a poverty index, the index was highly correlated to poverty alone (i.e., the percentage of the population below the poverty level)(Pearson correlation 0.91). Results did not differ when using the poverty index vs. poverty alone; however, effect sizes were stronger for the poverty index. It is possible that for Latinos, this comprehensive measurement of poverty is better than poverty alone as it accounts for education and type of work-variables that might be related to differential access to care. It is also possible that the stronger effect size observed with the index is because quartiles of the poverty index are based on the distribution of scores among the HIV-positive population, in contrast to commonly used poverty quartiles of the general population. Fourth, data available through surveillance records are limited. Therefore, we were unable to control for variables such as individuallevel socioeconomic status, health insurance, immigration status, or time in the US. Finally, our study examined Latinos diagnosed with HIV in Florida. The generalizability of the findings is therefore limited to this population.

\section{Conclusions}

Our study confirms disparities in mortality risk for Latinos with history of IDU and differing associated risk factors when compared with Latinos without history of IDU. Findings suggest that older age, late diagnosis, high Latino ethnic neighborhood density, and rural residence increase mortality risk for HIV-positive Latinos with history of IDU. 
Furthermore, black race and neighborhood poverty appear to be a strong predictor for mortality among Latinos without history of IDU, but not for Latinos with history of IDU.

\section{References}

Aidala AA, Lee G, Abramson DM, Messeri, P Siegler, A. Housing need, housing assistance, and connection to HIV care. AIDS Behav. 2007;11:S101-S115.

Alvarez KJ, Levy R. Health advantages of ethnic density for African American and Mexican American elderly individuals. Am J Public Health. 2012;102:2240-2242.

American Community Survey. 2011 American Community Survey 5-year estimates. American Community Survey United States Census Bureau, Washington, DC. Available at http://factfinder2.census.gov. 2014a. Retrieved Jan 2014.

American Community Survey. American Community Survey and Puerto Rico Community Survey 2011 code list. 2011. American Community Survey United States Census Bureau, Washington, DC. Available at http://www.census.gov/acs/www/Downloads/data_documentation/CodeLists/2011_ACS_ Code_Lists.pdf. 2014b. Retrieved Sept 2014.

Bécares L, Shaw R, Nazroo J, Stafford M, Albor C, Atkin K, Kiernan K, Wilkinson R, Pickett K. Ethnic density effects on physical morbidity, mortality, and health behaviors: a systematic review of the literature. Am J Public Health. 2012;102:e33-66.

Bécares L, Nazroo JY, Stafford M. The buffering effects of ethnic density on experienced racism and health. Health Place. 2009;15:670-678.

Benjamins MR, Kirby JB, Bond Huie SA. County characteristics and racial and ethnic disparities in the use of preventive services. Prev Med. 2004;39:704-712.

Boardman JD, Finch BK, Ellison CG, Williams DR, Jackson JS. Neighborhood disadvantage, stress, and drug use among adults. J Health Soc Behav. 2001;42:151-165.

Bouhnik AD, Chesney M, Carrieri P, Gallais H, Moreau J, Moati JP, Obadia Y, Spire B. Nonadherence among HIV-infected injection drug users: the impact of social instability. J Acquir Immune Defic Syndr. 2002;31(Suppl 3):S149-S153.

Buchanan D, Shaw S, Teng W, Hiser P, Singer M. Neighborhood differences in patterns of syringe access, use, and discard among injection drug users: implications for HIV outreach and prevention education. J Urban Health. 2003;80(3):438-454.

Centers for Disease Control and Prevention. Monitoring selected national HIV prevention and care objectives by using HIV surveillance data-United States and 6 US dependent 
areas-2011. HIV Surveillance Report Vol.18 (No. 5). US Department of Health and Human Services, Centers for Disease Control and Prevention, Atlanta, GA. Available at http://www.cdc.gov/hiv/pdf/2011_monitoring_hiv_indicators_hssr_final.pdf. 2013. Retrieved Sept 2014.

Centers for Disease Control and Prevention. NCHHSTP Atlas. Centers for Disease Control and Prevention, Atlanta, GA. Available at http://gis.cdc.gov/GRASP/NCHHSTPAtlas/main.html. 2014. Retrieved Dec 2014.

Cole SR, Lau B, Eron JJ, Brookhart MA, Kitahata MM, Marting JN, Mathews WC, Mugavero MJ. Estimation of the standardized risk difference and ratio in a competing risks framework: Application to injection drug use and progression to AIDS after initiation of antiretroviral therapy. Am J Epidemiol. 2015;181:238-245.

Das-Munshi J, Bécares L, Dewey ME, Stanfield SA, Prince MJ. Understanding the effect of ethnic density on mental health: multi-level investigation of survey data from England. BMJ. 2010;341:c5367.

Eschbach K, Ostir GV, Patel KV, Markides KS, Goodwin JS. Neighborhood context and mortality among older Mexican Americans: Is there a barrio advantage?. Am J Public Health. 2004;94:1807-1812.

Espinoza L, Hall HI, Selik RM, Hu X. Characteristics of HIV infection among Hispanics, United States 2003-2006. J Acquir Immune Defic Syndr. 2008;49:94-101.

Espinoza L, Hall HI, Hu X. Diagnosis of HIV infection among Hispanics/Latinos in 40 states and Puerto Rico, 2006-2009. J Acquir Immune Defic Syndr. 2012;60:205-213.

Florida Department of Children and Families. Substance abuse, Tallahassee, FL. Available at http://www.myflfamilies.com/service-programs/substance-abuse. 2014. Retrieved June 2015.

Florida Department of Health. HIV infection among those with an injection drug useassociated risk, Florida, 2014, Tallahassee, FL. Available at http://www.floridahealth.gov/diseases-and-conditions/aids/surveillance/_documents/hivaids-slide-sets/2014/idu-2014.pdf. 2014a. Retrieved April 2015.

Florida Department of Health. Cascade: The continuum of HIV care Florida, 2013, Tallahassee, FL. Available at http://www.floridahealth.gov/diseases-andconditions/aids/surveillance/_documents/hiv-aids-slide-sets/floridacontinuumofHIVCare-2013.pdf. 2014b. Retrieved June 2015.

Florida Department of Health. AIDS: patient care, Tallahassee, FL. Available at http://www.floridahealth.gov/diseases-and-conditions/aids/patient-care/index.html. n.d. Retrieved April 2015. 
Galea S, Ahern J, Vlahov D. Contextual determinants of drug use risk behavior: a theoretical framework. J Urban Health. 2003;80:iii50-iii58.

Gant Z, Bradley H, Hu X, Skarbinski J, Hall HI, Lansky A. Hispanics or Latinos Living with Diagnosed HIV: Progress Along the Continuum of HIV Care - United States, 2010. MMWR Morb Mortal Wkly Rep. 2014;63:886-890.

Genberg BL, Gange SJ, Go VF, Celentano DD, Kirk GD, Latkin CA, Mehta SH. The effect of neighborhood deprivation and residential relocation on long-term injection cessation among injection drug users (IDUs) in Baltimore, Maryland. Addiction. 2011;106:1966-1974.

Genereux M, Bruneau J, Daniel M. Association between neighbourhood socioeconomic characteristics and high-risk injection behaviour amongst injection drug users living in inner and other city areas in Montréal, Canada. Int J Drug Policy. 2010;21:49-55.

Halpern D, and Nazroo JY. The ethnic density effect: results from a national community survey of England and Wales. Int J Soc Psychiatry. 2000;46:34-46.

Hanna DB, Pfeiffer MR, Torian LV, Sackoff JE. Concurrent HIV/AIDS diagnosis increases the risk of short-term HIV-related death among persons newly diagnosed with AIDS, 2002-2005. AIDS Patient Care STDS. 2008;22:17-28.

Hogan JW, Tchernis R. Bayesian factor analysis for spatially correlated data, with application to summarizing area-level material deprivation from census data. J Am Statist Assoc. 2004;99:314-324.

Horberg MA, Hurley LB, Silverberg MJ, Klein DB, Quesenberry CP, Mugavero MJ. Missed office visits and risk of mortality among HIV-infected subjects in a large healthcare system in the United States. AIDS Patient Care STDS. 2013;27:442-449.

Inagami S, Borell LN, Wong MD, Fang J, Shapiro MF, Asch SM. Residential segregation and Latino, black and white mortality in New York City. J Urban Health. 2006;83:406-20.

Johnson TP, Bowman PJ. Cross-cultural sources of measurement error in substance use surveys. Subst Use Misuse. 2003;38:1447-1490.

Joy R, Druyts EF, Brandson EK, Lima VD, Rustad CA, Zhang W, Wood E, Montaner JS, Hogg RS. Impact of neighborhood-level socioeconomic status on HIV disease progression in a universal health care setting. J Acquir Immune Defic Syndr. 2008;47:500-505.

Kapadia F, Vlahov D, Donahoe RM, Friedland GF. The role of substance abuse in HIV disease progression: reconiling differences from laboratory and epidemiologic investigations. Clin Infect Dis 2005;41:1027-1034. 
Kirby JB, Toshiko K. Neighborhood socioeconomic disadvantage and access to health care. J Health Soc Behav. 2005;46:15-31.

Kohl M, Heinze G. PSHREG: A SASr macro for proportional and nonproportional substribution hazards regression with competing risk data. Medical University of Vienna, Spitalgasse, Vienna. Available at http://cemsiis.meduniwien.ac.at/fileadmin/msi_akim/CeMSIIS/KB/programme/tr08_201 2-PSHREG.pdf. 2012. Retrieved April 2014.

Krieger N, Chen JT, Waterman PD, Soobader MJ, Subramanian SV, Carson R. Geocoding and monitoring of US socioeconomic inequalities in mortality and cancer incidence: does the choice of area-based measure and geographic level matter? The public health disparities geocoding project (US). Am J Epidemiol. 2002;156:471-482.

Krieger N, Chen JT, Waterman PD, Soobader MJ, Subramanian SV, Carson R. Choosing area based socioeconomic measures to monitor social inequalities in low birth weight and childhood lead poisoning: the public health disparities geocoding project (US). J Epidemiol Commun Health. 2003a;57:186-199.

Krieger N, Waterman PD, Chen JT, Soobader MJ, Subramanian SV. Monitoring socioeconomic inequalities in sexually transmitted infections, tuberculosis, and violence: geocoding and choice of area-based socioeconomic measures-the public health disparities geocoding project (US). Public Health Rep. 2003b;118:240-260.

Langford SE, Anaworanich J, Cooper DA. Predictors of disease progression in HIV infection: a review. AIDS Res Ther 2007;4:11.

Maas B, Fairbairn N, Kerr T, Li K, Montaner JS, Wood E. Neighborhood and HIV infection among IDU: place of residence independently predicts HIV infection among a cohort of injection drug users. Health Place. 2007;13:432-439.

Martinez AN, Mobley LR, Lorvick J, Novak SP, Lopez AM, Kral AH. Spatial analysis of HIV positive injection drug users in San Francisco, 1987-2005. Int J Environ Res Public Health $2014 \mathrm{a} ; 11: 3937-3955$.

Martinez AN, Lorvick J, Kral AH. Activity spaces among injection drug users in San Francisco. Int J Drug Policy 2014b;25:516-524.

McFarland W, Chen S, Hsu L, Schwarcz S, Katz M. Low socioeconomic status is associated with a higher rate of death in the era of highly active antiretroviral therapy, San Francisco. J Acquir Immune Defic Syndr. 2003;33:96-103.

Messer LC, Laraia BA, Kaufman JS, Eyster J, Holzman C, Culhane J, Elo I, Burke JG, O'Campo P. The development of a standardized neighborhood deprivation index. J Urban Health 2006;83:1041-1062. 
Metsch LR, McCoy CB. Drug treatment experience: rural and urban comparison. Subst Use Misuse. 1999;34:763-784.

Nandi A, Glass TA, Cole SR, Chu H, Galea S, Celentano DD, Kirk GD, Vlahov D, Latimer WW, Mehta SH. Neighborhood poverty and injection cessation in a sample of injection drug users. Am J Epidemiol. 2010;171:391-398.

Niyonsenga T, Trepka MJ, Lieb S, Maddox LM. Measuring socioeconomic inequality in the incidence of AIDS: rural-urban considerations. AIDS Behav. 2013;17:700-709.

Nogueras M, Navarro G, Anton E, Sala M, Cervantes M, Amengual M, Segura F. Epidemiological and clinical features, response to HAART, and survival in HIV-infected patients diagnosed at the age of 50 or more. BMC Infect Dis. 2006;6:159.

Oramasionwu CU, Brown CM, Lawson KA, Ryan L, Frei CR. Evaluation HIV/AIDS disparities for blacks in the United States: a review of antiretroviral and mortality studies. J Natl Med Associ. 2009;101:1221-1229.

Rajabiun S, Rumptz MH, Felizzola J, Frye A, Relf M, Yu G, Cunningham WE. The impact of acculturation on Latino's perceived barriers to HIV primary care. Ethn Dis. 2008;18:403-408.

Schneider E, Whitmore S, Glynn MK, Dominguez K, Mitsch A, McKenna MT. Revised surveillance case definitions for HIV infection among adults, adolescents, and children aged $<18$ months and for HIV infection and AIDS among children aged 18 months to $<13$ years --- United States, 2008. MMWR Morb Mortal Wkly Rep. 2008;57:1-8.

Schwartz SJ, Des Rosiers S, Huang S, Zamboanga BL, Unger JB, Knight GP, Pantin H, Szapocznik J. Developmental trajectories of acculturation in Hispanic adolescents: associations with family functioning and adolescent risk behavior. Child Dev. 2013;84: 1355-1372.

Shaw RJ, Pickett KE, Wilkinson RG. Ethnic density effects on birth outcomes and maternal smoking during pregnancy in the US Linked Birth and Infant Death data set. Am J Public Health 2010;100:707-713.

Singh GK, Siahpush M. Increasing inequalities in all-cause and cardiovascular mortality among US adults aged 25-64 years by area socioeconomic status, 1969-1998. Int J Epidemiol. 2002;31:600-613.

Smith R, Rossetto K, Peterson BL. A meta-analysis of disclosure of one's HIV-positive status, stigma and social support. AIDS Care. 2008;20:1266-1275.

Sutton M, Anthony M, Vila C, McLellan-Lemal E, Weidle PJ. HIV testing and HIV/AIDS treatment services in rural counties in 10 southern states: Service provider perspectives. J Rural Health. 2010;26, 240-247. 
Trepka MJ, Niyonsenga T, Maddox LM, Lieb S. Rural AIDS diagnoses in Florida: changing demographics and factors associated with survival. J Rural Health. 2013a;29, 266-280.

Trepka MJ, Niyonsenga T, Maddox LM, Lieb S, Lutfi K, Pavlova-McCalla E. Community poverty and trends in racial/ethnic survival disparities among people diagnosed with AIDS in Florida, 1993-2004. Am J Public Health. 2013b;103:717-726.

Trepka MJ, Fennie KP, Pelletier V, Lutfi K, Lieb S, Maddox M. Migration patterns among Floridians with AIDS, 1993-2007: implications for HIV prevention and care. South Med J. 2014;107:531-539.

United States Census Bureau. Geography: ZIP Code Tabulation Areas (ZCTAs). United States Census Bureau, Washington, DC. Available at http://www.census.gov/geo/reference/zctas.html. n.d. Retrieved April 2013.

Whitley R, Prince M, McKenzie K, Stewart R. Exploring the ethnic density effect: a qualitative study of a London electoral ward. Int J Soc Psychiatry. 2006;52:376-91.

Williams CT, Latkin CA. Neighborhood socioeconomic status, personal network attributes, and use of heroin and cocaine. Am J Prev Med. 2007;32(Suppl 6):S203-10.

WWAMI Rural Health Research Center. Rural Urban Commuting Areas (RUCA). WWAMI Rural Health Research Center, Seattle, WA. Available at http://depts.washington.edu/uwruca/. n.d. Retrieved Sept 2014.

Zukoski AP, Thorburn S. Experiences of stigma and discrimination among adults living with HIV in a low HIV prevalence context: A qualitative analysis. AIDS Patient Care STDS. 2009;23:267-276. 


\section{Tables and figures}

FIGURE 1. Survival probability curves for Latinos reported with HIV by history of injection drug use (IDU), Florida, 2000-2011

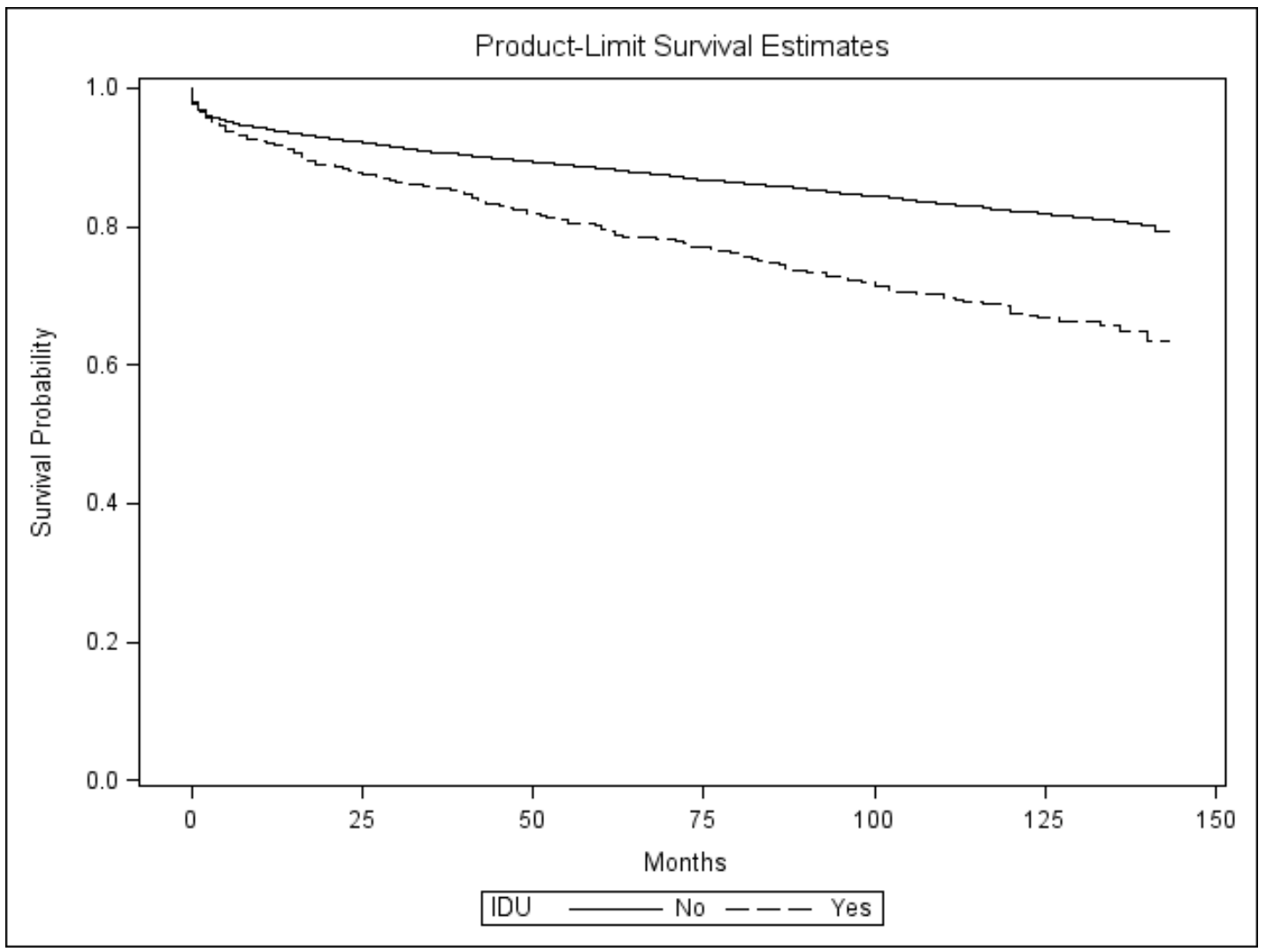


TABLE 1. Characteristics of Latinos 13 years and older reported with HIV with a history of injection drug use vs. no history of injection drug use, Florida, 2000-2008

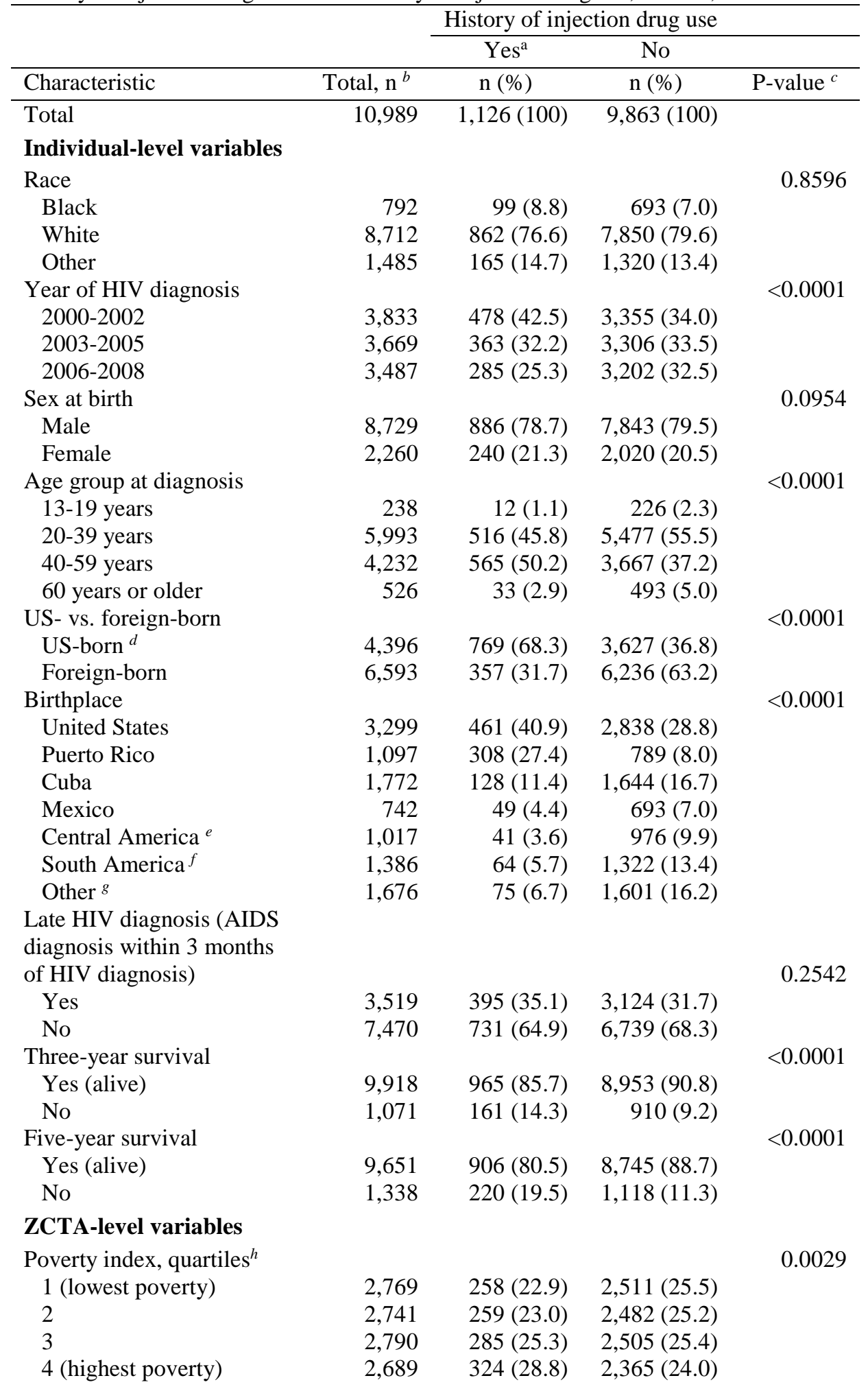


Percent of population who

self-identified as

Hispanic/Latino

$\geq 50$
$25-49$
$<25$
RUCA classification
Rural
Urban

$\begin{array}{lll}4,111 & 331(29.4) & 3,780(38.3) \\ 3,307 & 347(30.8) & 2,960(30.0) \\ 3,571 & 448(39.8) & 3,123(31.7)\end{array}$

$<0.0001$

US=United States; ZCTA=ZIP code tabulation area; SES=socioeconomic status; RUCA=Rural-Urban Commuting Area. Percentages may not add up to 100 due to rounding.

${ }^{a}$ Includes cases reported as both injection drug use and both male-to-male sexual contact and injection drug use.

${ }^{b}$ Excludes cases diagnosed in a correctional facility, missing residential zip code at time of HIV diagnosis, or diagnosed under the age of 13.

${ }^{c}$ P-value for individual-level variables from Cochran-Mantel-Haenszel test controlling for residential zip code. P-value for neighborhood-level variables from chi-square test.

${ }^{d}$ Category includes cases born in any of the 50 US states, District of Columbia, or any US dependency.

${ }^{e}$ Includes cases born in the following countries: Costa Rica, El Salvador, Guatemala, Honduras, Nicaragua, and Panama.

${ }^{r}$ Includes cases born in the following countries: Argentina, Bolivia, Chile, Colombia, Ecuador, Paraguay, Peru, Uruguay, and Venezuela.

${ }^{g}$ Includes cases identified as "Hispanic/Latino" and born in countries other than the United States, Puerto Rico, Mexico, Cuba, Central American and South America with the exception of Brazil. This category includes cases born in Brazil and the Dominican Republic.

${ }^{\mathrm{h}}$ SES quartiles of standardized SES scores of the HIV-positive Latino population. 
TABLE 2. Weighted multilevel Cox regression hazard ratios for mortality and 95\% confidence intervals for Latinos reported with HIV by history of injection drug use, Florida, 2000-2011

\begin{tabular}{|c|c|c|c|c|}
\hline \multirow[b]{3}{*}{ Characteristic } & \multicolumn{4}{|c|}{ History of injection drug use } \\
\hline & \multicolumn{2}{|c|}{ Yes } & \multicolumn{2}{|c|}{ No } \\
\hline & $\begin{array}{c}\text { Crude HR } \\
\text { (95\% CI) }\end{array}$ & $\begin{array}{c}\text { aHR } \\
(95 \% \mathrm{CI})\end{array}$ & $\begin{array}{l}\text { Crude HR } \\
(95 \% \text { CI) }\end{array}$ & $\begin{array}{c}\text { aHR } \\
(95 \% \mathrm{CI})\end{array}$ \\
\hline \multirow{2}{*}{\multicolumn{5}{|c|}{$\begin{array}{l}\text { Individual- } \\
\text { level variables } \\
\text { Race }\end{array}$}} \\
\hline & & & & \\
\hline Black & $0.99(0.70-1.38)$ & $0.88(0.54-1.14)$ & $1.85(1.61-2.12)$ & $1.63(1.40-1.88)$ \\
\hline White & Referent & Referent & Referent & Referent \\
\hline Other & $0.37(0.26-0.51)$ & $0.29(0.20-0.40)$ & $0.14(0.11-0.18)$ & $0.12(0.09-1.15)$ \\
\hline \multicolumn{5}{|l|}{$\begin{array}{l}\text { Year of HIV } \\
\text { diagnosis }\end{array}$} \\
\hline $2000-2002$ & $1.28(0.90-1.85)$ & $1.47(1.03-2.13)$ & $1.38(1.18-1.62)$ & $1.85(1.58-2.18)$ \\
\hline 2003-2005 & $1.05(0.73-1.55)$ & $1.07(0.74-1.58)$ & $1.18(1.01-1.40)$ & $1.13(0.96-1.33)$ \\
\hline 2006-2008 & Referent & Referent & Referent & Referent \\
\hline \multicolumn{5}{|l|}{ Sex at birth } \\
\hline Male & $1.03(0.82-1.32)$ & $0.87(0.68-1.12)$ & $1.03(0.82-1.32)$ & $1.07(0.95-1.21)$ \\
\hline Female & Referent & Referent & Referent & Referent \\
\hline \multicolumn{5}{|l|}{$\begin{array}{l}\text { Age group at } \\
\text { diagnosis }\end{array}$} \\
\hline 13-19 years & Referent & Referent & Referent & Referent \\
\hline 20-39 years & $4.06(0.90-75.56)$ & $3.81(0.83-71.09)$ & $1.30(0.87-2.05)$ & $1.29(0.87-2.04)$ \\
\hline $40-59$ years & $7.32(1.62-75.56)$ & $6.48(1.41-121.05)$ & $2.43(1.63-3.83)$ & $2.13(1.42-3.36)$ \\
\hline $\begin{array}{l}60 \text { years or } \\
\text { older }\end{array}$ & 24.54 (5.16-462.79) & $18.75(3.83-356.45)$ & $6.72(4.44-10.73)$ & $5.97(3.92-9.58)$ \\
\hline \multicolumn{5}{|l|}{ Birthplace } \\
\hline United States & Referent & Referent & Referent & Referent \\
\hline Puerto Rico & $1.18(0.93-1.49)$ & $1.06(0.83-1.34)$ & $1.27(1.07-1.50)$ & $1.09(0.92-1.29)$ \\
\hline Cuba & $1.43(1.06-1.90)$ & $0.96(0.68-1.33)$ & $1.52(1.33-1.74)$ & $1.04(0.90-1.20)$ \\
\hline $\begin{array}{l}\text { Mexico } \\
\text { Central }\end{array}$ & $0.82(0.45-1.37)$ & $0.72(0.39-1.21)$ & $0.89(0.71-1.09)$ & $0.90(0.72-1.12)$ \\
\hline $\begin{array}{c}\text { America } \\
\text { South }\end{array}$ & $0.53(0.23-1.03)$ & $0.38(0.16-0.74)$ & $0.81(0.67-0.98)$ & $0.69(0.57-0.84)$ \\
\hline America & $0.18(0.07-0.40)$ & $0.20(0.07-0.45)$ & $0.49(0.40-0.59)$ & $0.50(0.41-0.61)$ \\
\hline Other & $0.74(0.46-1.14)$ & $0.56(0.33-0.88)$ & $0.77(0.66-0.89)$ & $0.75(0.64-0.88)$ \\
\hline \multicolumn{5}{|l|}{$\begin{array}{l}\text { Late HIV } \\
\text { diagnosis } \\
\text { (AIDS } \\
\text { diagnosis } \\
\text { within } 3 \\
\text { months of HIV } \\
\text { diagnosis) }\end{array}$} \\
\hline Yes & $2.03(1.67-2.48)$ & $2.31(1.87-2.86)$ & $2.34(2.12-2.57)$ & $2.27(2.06-2.50)$ \\
\hline No & Referent & Referent & Referent & Referent \\
\hline \multicolumn{5}{|l|}{$\begin{array}{l}\text { ZCTA-level } \\
\text { variables } \\
\text { Poverty index, } \\
\text { quartiles }\end{array}$} \\
\hline & Referent & Referent & Referent & Referent \\
\hline
\end{tabular}




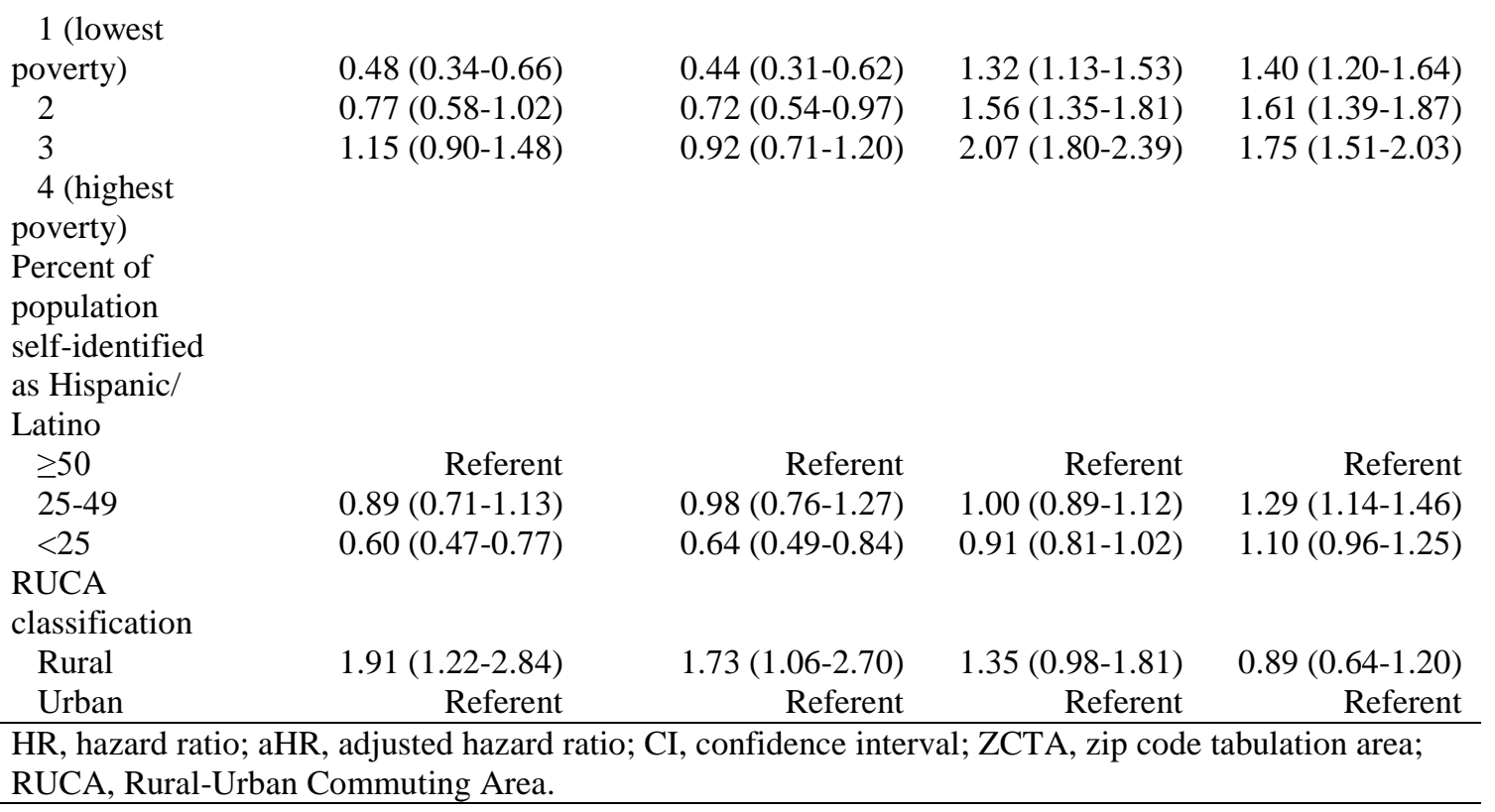




\title{
MANUSCRIPT 3
}

(C) Copyright 2016

Sheehan DM, Trepka MJ, Fennie KP, Dillon FR, Madhivanan P, Maddox LM. Neighborhood Latino ethnic density and mortality among HIV-positive Latinos by birth country/region, Florida, 2005-2008. Ethnicity \& Health. [Epub ahead of print].

\begin{abstract}
Objective: Lower mortality for Latinos has been reported in high Latino density areas. The objective was to examine the contribution of neighborhood Latino density to mortality among HIV-positive Latinos. Methods: Florida HIV surveillance data for 2005-2008 were merged with 2007-2011 American Community Survey data using zip code tabulation areas. Hazard ratios (HR) were calculated using multi-level weighted Cox regression and adjusted for individual-level factors and neighborhood poverty. Results: Of 4649 HIV-positive Latinos, 11.8\% died. There was no difference in mortality risk across categories of Latino ethnic density for Latinos as a whole. There were subgroup effects wherein mortality risk differed by ethnic density category for Latinos born in some countries/regions. Residing in an area with $\geq 50 \%$ Latinos compared with $<25 \%$ was associated with increased mortality risk for Latinos born in Puerto Rico (HR 1.67; 95\% CI [1.01-2.70]). Residing in an area where Mexicans were the majority Latino group was associated with increased mortality risk for Latinos born in Mexico (HR 3.57; 95\% CI [1.43-10.00]). Conclusions: The survival advantage seen among the Latino population in high Latino density areas was not seen among HIV-positive Latinos. Research is needed to determine if this may be related to stigma or another mechanism.
\end{abstract}


Keywords: Latino, human immunodeficiency virus, ethnic density, mortality, neighborhood

\section{Introduction}

In 2010, the age-adjusted all-cause mortality rate for the general Latino population in the United States (US) was lower than for non-Latino whites (559 vs. 755 per 100000 population, respectively) (National Center for Health Statistics, 2014). Yet, the mortality rate for Latinos with human immunodeficiency virus (HIV) was more than 2.5 times the rate of their non-Latino white counterparts (female: 1.1 vs. 0.4 per 100 000; male: 4.6 vs. 1.8 per 100 000, respectively) (National Center for Health Statistics, 2014). Further disparities have been reported among Latino immigrants of varying birth countries/regions. The 3-year survival rate in the US for foreign-born Latinos diagnosed with acquired immune deficiency syndrome (AIDS) between 2001 and 2005 was 88\% (95\% confidence interval (CI) [88-89]) compared with 91\% (95\% CI [90-91]) for USborn Latinos (Espinoza et al., 2012). HIV-positive Latinos born in Puerto Rico were at the highest risk of mortality when compared with HIV-positive Latinos born in mainland US (Espinoza et al., 2012, Hanna et al., 2008).

Research suggests that racial/ethnic minorities who live among people of their own ethnic group experience health benefits. In the US, the protective effect of ethnic density (the proportion of an ethnic group in a defined area) has most consistently been reported for Latinos (Becares et al., 2012). A study in New York City found a 3 per 100 000 population decrease in all-cause mortality per $1 \%$ increase in Latino ethnic density among Latino men, even after controlling for neighborhood socioeconomic status 
(Inagami et al., 2006). A study in Texas reported lower risk of all-cause mortality for Mexican-Americans living in census tracts with a higher percentage of MexicanAmericans compared with Mexican-Americans living in census tracts with a lower percentage of Mexican-Americans (hazard ratio (HR) 0.64; 95\% CI [0.42-0.96]) (Eschbach et al., 2004). This effect persisted after controlling for age, gender, health status, and disability and despite the lower socioeconomic status of the high density neighborhoods. Additional benefits of ethnic density for Latinos have been reported for heart disease (Alvarez \& Levy, 2012) and mortality (Franzini \& Spears, 2003); stroke; lung, breast and colorectal cancer (Franzini \& Spears, 2003, Eschbach, et al., 2005); smoking during pregnancy (Shaw et al., 2010), infant mortality (Shaw et al., 2010, Jenny, et al., 2001), preterm birth (Mason et al., 2010, Masi et al., 2007), and low birth weight (Masi et al., 2007, Peak \& Weeks, 2002); depression (Gerst et al., 2011, Sheffield \& Peek, 2009, Ostir et al., 2003); poor self-rated health (Patel et al., 2003, Shaw \& Pickett, 2011); cholesterol screening (Benjamins et al., 2004); and access to care (Haas et al., 2004). Empirical data suggest that ethnic density might work through decreased exposure to racism (Whitley et al., 2006, Becares et al., 2009) and discrimination (Whitley et al., 2006, Becares et al., 2009, Das-Munshi et al., 2010); improved social support (DasMunshi et al., 2010, Halperin \& Nazroo, 2000), social cohesion (Hong et al., 2014) and social networks (Whitley et al., 2006, Becares et al., 2009, Das-Munshi et al., 2010); and increased access to care (Benjamins et al., 2004, Haas et al., 2004) and culturally appropriate resources (Whitley et al., 2006). Other proposed mechanisms include decreased levels of socially induced stress (Eschbach et al., 2004) and social stigma (Pickett \& Wilkinson, 2008), improved access to and dissemination of health information 
through informal interactions (Lee, 2009), and higher numbers of language/culturalconcordant physicians (White et al., 2012).

Despite evidence of a protective effect of Latino ethnic density for Latinos, no studies to date have examined the relationship between ethnic density and HIV/AIDS or other infectious diseases. Since the development of highly active antiretroviral therapy (HAART), HIV has become a chronic condition requiring life-long medical care. Social support (informational, tangible or emotional) from friends and family has been found to encourage HIV seropositive status disclosure (Smith et al., 2008), improve quality of life and mental health (Friedland et al., 1996, Swindells et al., 1999), and increase retention in HIV care (Catz et al., 1999) and medication adherence (Edwards, 2006) among persons with HIV. It is possible, based on findings for the general Latino population and for Latinos with non-communicable diseases, that the social support provided by a predominantly Latino neighborhood could offer long-term assistance to Latinos with HIV. Furthermore, a relationship between neighborhood Latino ethnic density and survival for Latinos with HIV could also provide some insight on availability of culturally appropriate care and resources in high and low Latino ethnic density areas. Finally, Latinos in the US differ in socioeconomic status, health care access (Motel \& Patten, 2012), and outcomes along the HIV/AIDS care continuum (Espinoza et al., 2008). Despite the heterogeneity among Latinos in the US, most studies examine Latinos as one group. Although some studies have examined ethnic density among certain Latino ethnic groups (i.e. Mexicans), we were unable to identify studies that examined and compared the effect of ethnic density for Latinos from other birth countries/regions. Therefore, the objective of this study was to examine the role of neighborhood Latino ethnic density in 
all-cause mortality among Latinos diagnosed with HIV in Florida. Further, we sought to (1) compare the role of Latino ethnic density in mortality within Latinos of varying birth countries/regions and (2) determine if Latino ethnic density ameliorates disparities within Latinos.

\section{Methods}

Study sample

De-identified HIV surveillance data were obtained from the Florida Department of Health (FDOH) Enhanced HIV/AIDS Reporting System (eHARS). Latinos ages 13 and over who met the Centers for Disease Control and Prevention (CDC) case definition for HIV (Centers for Disease Control and Prevention, 1999, 2008) between 2005 and 2008 were included ( $N=5061)$. Cases were followed through December 31, 2011 for mortality from any cause. Individuals alive at the end of the follow-up period were censored (mean follow-up for censored cases $=59$ months). Vital status was ascertained from the FDOH's Office of Vital Statistics, the Social Security Administration's Death Master File, and the National Death Index. Cases with missing or invalid data for zip code at time of HIV diagnosis $(n=282)$, diagnosed under the age of $13(n=14)$, missing month of HIV diagnosis $(n=10)$, and cases diagnosed in a correctional facility $(n=106)$ were excluded. Cases diagnosed in a correctional facility were excluded because neighborhood characteristics obtained from the American Community Survey are representative of individuals residing in each ZCTA, and not of individuals residing in correctional facilities. Furthermore, individuals residing in correctional facilities may have limited interaction with the adjacent neighborhood and different access to resources 
and health care than the surrounding community. A total of 4649 Latinos diagnosed with HIV between 2005-2008 met the inclusion criteria and were included in the analyses. Of these, 548 (11.8\%) died within the follow-up period, and the remaining 4101 (88.2\%) were censored.

Individual- and neighborhood-level variables

The following variables were extracted from eHARS: sex at birth; age at HIV diagnosis; birth country; HIV diagnosis month and year; HIV transmission mode; HIVto-AIDS interval in months (if case progressed to AIDS); month and year of death; residential zip code at time of HIV diagnosis; and whether the case was diagnosed at a correctional facility. Zip code at time of HIV diagnosis (e.g. at the start of the follow-up period) was used instead of zip code at time of death for two reasons: (1) zip code at time of death is not complete from all sources of death reports, and (2) zip code at the end of the follow-up period is not available for cases who did not die. Neighborhood characteristics were obtained from the 2007-2011 American Community Survey (ACS) (US Census Bureau, 2014). Zip codes were matched to a corresponding zip code tabulation area (ZCTA). ZCTAs are generalized areal representations of zip code service areas used by the ACS to tabulate summary statistics (US Census Bureau, 2013). Cases in our cohort resided in 530 unique ZCTAs at time of HIV diagnosis. The following neighborhood characteristics were extracted at the ZCTA-level: percent of population below poverty line; percent of population 16 and older unemployed; percent of population 18 and older that was a high school graduate; percent of population who identified themselves as Hispanic/Latino; and percent of Hispanic/Latino population who 
identified themselves as either Puerto Rican, Mexican, Cuban, Central American, or South American (separately).

Analysis

Latinos were categorized into one of the following birth countries/regions: USborn (excludes Puerto Rico), Puerto Rico, Mexico, Cuba, Central America, South America, and other. First, we conducted a descriptive analysis of individual and neighborhood-level factors by birth country/region (table 1). For this part of the analysis, neighborhood-level poverty, education and unemployment were divided into quartiles based on the Florida population. Among Latinos, a strong ethnic density effect has been reported in areas with 50\% Latinos or more (Alvarez \& Levy, 2012, Shaw et al., 2010). For this reason, and to address small cell sizes in the analysis by birth country/region, we categorized Latino ethnic density into 3 categories: $<25 \%, 25-49 \%$, and $\geq 50 \%$. Given the heterogeneity of Latinos, we also sought to determine the importance of being surrounded by people of their specific ethnic origin (e.g. Cuban, Puerto Rican, Mexican, etc.). To examine this, we categorized cases as either ethnically congruent or not. We defined ethnic congruency as birth in the same country/region as the majority Latino group in the ZCTA. For example, a case born in Mexico was considered to be ethnically congruent if they lived in a ZCTA where the largest ethnic group among Latinos was Mexican.

Second, we explored the role of Latino ethnic density in all-cause mortality for Latinos as a whole and for each birth country/region separately (table 2). Highly correlated covariates can cause variables to appear non-significant in survival analyses 
(Cantor, 2003). Thus, prior to model building, we examined the correlation between neighborhood SES variables (poverty, high school graduation, and unemployment) and between SES variables and ethnic density. Correlation between neighborhood poverty and high school graduation was high (Pearson coefficient $=-0.81$ ). Correlation was lowest for ethnic density and poverty (poverty $=0.15$; unemployment $=-0.25$; high school graduation $=-0.49)$. Exploratory principal component analysis showed that poverty accounted for most of the variability in SES variables. Therefore, we used only poverty as a continuous variable to control for neighborhood SES in regression analyses. Kaplan-Meier survival curves were generated by birth country/region, poverty level, and ethnic density category. The Cox regression model's proportional hazards assumption was violated. Therefore, SAS macro PHSREG by Kohl and Heinze (Kohl \& Heinze, 2014) was used to run weighted Cox models. Weighted Cox regression models address non-proportionality by calculating an average hazard ratio when the hazard varies in time while taking into account the decreasing number of cases throughout the follow-up period (Schemper et al., 2009). There are at least 2 limitations to this method. First, it requires a larger sample size than the proportional Cox model. Still, the method has provided appropriate results with samples of $n=80$ (our smallest group contains 324 cases) (Schemper et al., 2009). Second, the weighted Cox model is a nonparametric test. If nonproportionality is negligible, the proportional Cox model, as a parametric test, might be more robust to detect an effect. Multi-level (level 1: individual; level 2: ZCTA) modeling was used to account for correlation among cases living in the same ZCTA. Hazard ratios were calculated by ethnic density category and adjusted for all individual-level variables and neighborhood poverty. 
Third, we tested whether Latino ethnic density reduced disparities within Latinos of varying birth countries/regions (table 3) using US-born Latinos as a referent group (Espinoza et al., 2012, Hanna et al., 2008). We compared 4 models: (1) unadjusted, (2) adjusted for individual-level variables, (3) adjusted for individual-level variables and neighborhood poverty, and (4) adjusted for individual-level variables, poverty (continuous) and ethnic density. During this analysis only, Latino ethnic density was entered as a continuous variable consistent with the ethnic density literature (Inagami et al., 2006, Eschbach et al., 2004, Franzini \& Spears, 2003, Peak \& Weeks, 2002, Patel et al., 2003, Shaw \& Pickett, 2011) in an effort to fully adjust for this variable and avoid any loss of data during categorization.

Finally, we examined the role of ethnic congruency in mortality. Given our hypothesis that ethnic congruency is protective, we used Latinos diagnosed in a ZCTA where the majority Latino group was of their same ethnic origin as the referent group. Only foreign-born Latinos were included in this analysis because surveillance data does not provide country of origin for US-born Latinos. Hence, it was not possible to determine if a case born in the US was ethnically congruent to the majority Latino group in their neighborhood. Latinos born in "other” countries were also excluded because they partially represent Latinos with unknown birth country/region. For foreign-born Latinos, hazard ratios were adjusted for individual-level variables and neighborhood poverty. All models included year of HIV diagnosis in an effort to control for secular changes in clinical treatment and policy related to healthcare access and HIV/AIDS. This study was approved by the Florida Department of Health and the Florida International University Institutional Review Boards. 


\section{Results}

In Florida, there were 4649 Latinos diagnosed with HIV between 2005 and 2008 who met the inclusion criteria. Of these, $11.8 \%$ died within the follow-up period. While $32 \%$ were born in mainland US, the second largest ethnic group was Latinos born in Cuba (16.2\%) (table 1). HIV-positive Latinos of varying birth countries/regions differed significantly in gender, age, HIV transmission mode, HIV-to-AIDS interval, and survival length. A larger proportion of Latinos born in Central America (55\%) resided in ZCTAs in the highest poverty quartile when compared with all other Latino groups. A smaller proportion of South Americans (21\%) resided in ZCTAs in the highest poverty quartile when compared with all other groups including Latinos born in mainland US (36.6\%). Of all HIV-positive Latinos, $36.7 \%$ resided in a ZCTA where $\geq 50 \%$ of the population identified themselves as “Hispanic/Latino.” A larger proportion of Latinos born in Cuba (66.6\%) resided in the highest ethnic density category $(\geq 50 \%)$ when compared with all other groups. Of foreign-born Latinos, 21.7\% lived in a ZCTA congruent with their specific ethnicity. The majority of Latinos born in Cuba (70.2\%) lived in a ZCTA where Cubans were the largest Latino group. No cases born in Central America experienced ethnic congruency.

There was no difference in mortality risk by Latino ethnic density category for Latinos as a whole after controlling for individual-level factors and neighborhood poverty. Latinos born in Puerto Rico who resided in a ZCTA with $<25 \%$ Latinos experienced a decreased mortality risk when compared with Latinos born in Puerto Rico who resided in a ZCTA with $\geq 50 \%$ Latinos (HR 0.60; 95\% CI [0.37-0.99]) (Table 2). 
Differences in mortality by ethnic density category were not identified for other Latino groups. Compared to Latinos born in mainland US, those born in Puerto Rico had an increased mortality risk (HR 2.00; 95\% CI [1.53-2.59]), and those born in South America had a decreased mortality risk (HR 0.60; 95\% CI [0.40-0.89]) after controlling for individual-level factors and neighborhood poverty. Disparities were not reduced after controlling for ethnic density (table 3).

Ethnic congruency did not affect mortality risk for foreign-born Latinos as a whole after controlling for individual-level variables and neighborhood poverty (HR 0.97; 95\% CI [0.76-1.24]) (data not in table). Latinos born in Mexico who lived in a ZCTA where Mexicans were not the majority Latino group were at decreased mortality risk compared with Latinos born in Mexico who lived in a ZCTA where the majority Latino group was Mexican (HR 0.28; 95\% CI [0.10-0.70]). Ethnic congruency did not affect mortality for other Latinos born outside mainland US (Puerto Rico HR 1.03, 95\% CI [0.65-1.67]; Cuba HR 1.10, 95\% CI [0.68-1.74]; South American HR 1.81, 95\% CI [0.70-5.68]).

\section{Discussion}

The results of this study indicate that neighborhood Latino ethnic density is not associated with mortality among HIV-positive Latinos. Sensitivity analysis showed consistent results when comparing very high ethnic density (>90\%) with low ethnic density (<10\%) (HR 0.90, 95\% CI [0.60-1.35]) as well as using ethnic density as a continuous variable (HR 1.00 per 5 unit increase, 95\% CI [0.98-1.02]). Previous studies found evidence of lower all-cause, heart disease (Franzini \& Spears, 2003), and infant 
(Shaw et al., 2010) mortality for Latinos in the US who live in higher Latino density areas. Our findings suggest that the relationship between ethnic density and mortality may be more complex, particularly for mortality from stigmatizing conditions. While the mechanisms of ethnic density -lower discrimination (Whitley et al., 2006, Das-Munshi et al., 2010), socially induced stress (Eschbach et al,. 2004) and stigma (Pickett \& Wilkinson, 2008), and improved social support (Das-Munshi et al., 2010, Halpern \& Nazroo, 2000), cohesion (Hong et al., 2014) and networks (Whitley et al., 2006, DasMunshi et al., 2010)- might enhance the protective Latino values of familismo (a value emphasizing close, supportive family relationships) (Campos et al., 2014) and personalismo (a value emphasizing warm, empathetic personal interactions) (Lopez-Class et al., 2011) to improve health, they challenge many social aspect of HIV/AIDS. High levels of perceived stigma (Varas-Diaz et al., 2005) and low levels of HIV serostatus disclosure (Zee et al., 2004) increase isolation among Latinos (Varas-Diaz et al., 2005) and might prevent them from taking advantage of the surrounding Latino community. Stigma (Darrow et al., 2009) and low levels of HIV/AIDS knowledge (Ritieni et al., 2008) among the general Latino population might also prevent a Latino community from supporting individuals with HIV/AIDS. It is important to note that higher Latino density has been found to be protective in non-stigmatizing conditions and that effect may not extend to conditions like HIV/AIDS.

The findings of this study also suggest that the relationship between Latino ethnic density and mortality differs for Latinos by birth country/region. Results showed a significant association between Latino ethnic density and mortality only for Latinos born in Puerto Rico. It should be noted, however, that the effect was marginally significant 
(HR 0.60, 95\% CI [0.37-0.99]). A study among Puerto Ricans with HIV/AIDS reported that stigma negatively influenced social interactions leading to loss of social support and isolation (Varas-Diaz et al., 2005). It is possible that HIV-positive Latinos born in Puerto Rico who live in Latino dense areas experience more stigma compared with their counterparts surrounded by a majority non-Latino neighborhood.

Latino ethnic density did not partially account for disparities in mortality seen between HIV-positive Latinos of varying birth countries/regions. Hazard ratios changed negligibly in Model 4 after controlling for ethnic density. The finding that Latinos born in Puerto Rico have an increased mortality risk compared with Latinos born in mainland US is consistent with the literature (Espinoza et al., 2012, Hanna et al., 2008, Espinoza et al., 2008). Our analysis controlled for HIV transmission mode and therefore presumably accounted for the higher rates of injection drug use reported by this Latino group (Espinoza et al., 2008, 2012). By controlling for delayed HIV diagnosis (HIV-to-AIDS interval $<1$ month), we attempted to adjust for the disparities in late diagnosis seen among Latinos of varying birth countries/regions that range from 35\% among Latinos born in Cuba to 58\% among those born in Central America (Espinoza et al., 2008). Our findings still may reflect some differences in late diagnosis, as well as differences in rate of disease progression, delayed linkage to and/or retention in care, and access to and/or adherence to antiretroviral treatment. The unique opportunity to travel back and forth between mainland US and Puerto Rico might cause detrimental disruption in HIV care leading to poor health outcomes (Taylor et al., 2014). In addition, Puerto Ricans report lower median household income and have the second highest poverty rate among the 10 largest Latino ethnic subgroups (Motel et al., 2012). Although they also report higher 
educational attainment and rates of health insurance coverage, individual-level income and poverty may be indirectly contributing to the disparities we see between Latinos born in Puerto Rico and those born in mainland US.

The dataset used for this study did not include individual-level SES. In an effort to control for individual-level SES and other potential unmeasured confounders, we conducted post hoc sensitivity analysis of unobserved confounding using Propensity Score Calibration (Lanehart et al., 20012, Sturmer et al., 2005). Only one association changed after controlling for unobserved confounding. During our original analysis, we found no difference in risk of mortality between Latinos born in Cuba compared with Latinos born in the US after adjusting for individual- and neighborhood-level covariates available in our dataset (table 3, model 4) (HR 1.14, CI 0.85-1.52). When we adjusted for unobserved confounders using the propensity scores, we found Latinos born in Cuba to be at increased mortality risk (HR 1.14, CI 1.02-1.27). This is consistent with findings from Espinoza et al. (2008) reporting lower 12- and 36-month survival after AIDS diagnosis for Latinos born in Cuba compared with those born in the US. Covariates that were not measured in this study appear to be confounding the association between birth country and mortality for Latinos born in Cuba.

Finally, this study identified a decreased mortality risk for Latinos born in Mexico who resided in ZCTAs where Mexican-Americans were not the majority Latino group. Areas where Mexicans are the majority Latino group might correlate with migrant workers and rural status. In our study, 54\% of rural cases lived in an area where Mexicans were the majority Latino group. Nevertheless, the effect of ethnic congruency 
on Latinos born in Mexico persisted after excluding rural cases (HR 0.34, 95\% CI [0.120.89]). Post hoc analysis revealed that Latinos born in Mexico were the only group who did poorly in areas where Mexicans were the majority Latino group. This is surprising given the protective effects of ethnic density on all-cause and heart disease mortality found in two Texas studies (Eschbach et al., 2004, Franzini \& Spears, 2003). One study specifically examined Mexicans in high Mexican-American density areas (Eschbach et al., 2004). However, these studies did not involve the interplay between stigma, community and health. Our results do support findings reported by Jenny et al (2001). In this study, infants born to US-born Mexican mothers had a decreased mortality risk but those born to Mexican-born mothers had an increased mortality risk with increasing Mexican ethnic density.

Our study has several limitations. First, sample size for some Latino groups was not ideal. In an evaluation of ethnic density studies, Shaw et al. suggested that ethnic density studies with a sample size of $<500$ tended to have neutral findings (Shaw et al. 2012). This potential limitation only affects our results for Latinos born in Puerto Rico, Mexico, and Central America. However, Shaw and colleagues also showed that sample sizes $>4000$ tended to show protective effects. Therefore, it is important to note that we failed to find an association with a sample of 4649 for Latinos as a whole. The small number of deaths in some Latino groups may have also limited our power to find an association. Second, we were unable to examine ethnic density for smaller geographic units (e.g. census blocks) as only zip code data were available. In 2002, Krieger and colleagues reported that zip codes might fail to properly account for socioeconomic status compared to census tracts and block groups in Rhode Island and Massachusetts (Krieger 
et al., 2002). However, this was found for cancer incidence rates only; zip codes worked well for all-cause mortality rates. Nonetheless, Latino ethnic density has been shown to provide benefits among Latinos in larger geographic areas (Shaw et al., 2010, Jenny et al. 2001). Third, our dataset did not allow us to determine ethnic origin for US-born Latinos. Therefore, we could not study ethnic congruency in this group. Fourth, as mentioned previously, we did not have data on individual-level SES and were unable to adjust for this in the analysis. However, Latino ethnic density has been found to be an independent predictor of mortality among Latinos after controlling for individual-level SES (Eschbach et al., 2004). Fifth, we did not have information on how long cases lived at the reported zip code. Thus, we were unable to determine the length of time that cases were exposed to the ethnic density level used in the analysis. Sixth, there is a possibility that Latinos who become ill return to their home country. This would cause incomplete death data for foreign-born Latinos and underestimate mortality rates for this group. There is no reason to believe that back-migration differs by ethnic density level and therefore this only limits our study of disparities by birth country/region. Even so, research suggests that the apparent mortality advantage of foreign- versus US-born Latinos does not hold for Latinos with HIV/AIDS (Ruiz et al., 2013). Finally, our findings may not be generalizable to the foreign-born US Latino population as our sample of foreign-born Latinos was predominantly Cuban. However, the diversity of Florida's Latino population allowed us to examine Latinos of varying birth countries/regions. Additionally, using a Florida sample allowed us to study high levels of ethnic density because $20 \%$ of ZCTAs were comprised of 25\% Latinos or more (US Census Bureau, 2014). 
It is important that future ethnic density research is able to incorporate information on the length of time a case is exposed to a particular neighborhood, as well as mobility patterns of the population under study. Additionally, the level of interaction with neighbors, involvement with community events, and availability and access to structural resources are important considerations. Future HIV/AIDS and ethnic density research would benefit from information regarding levels of community HIV/AIDS knowledge and stigma, and neighborhood HIV/AIDS resources.

\section{Conclusions}

To our knowledge, this study is the first to examine the role of ethnic density in mortality among HIV-positive Latinos. Results suggest that HIV-positive Latinos do not benefit from the protective effect of Latino ethnic density. Many ethnic density studies have been conducted among Mexican-Americans (Eschbach et al., 2004, Jenny et al., 2001, Peak \& Weeks, 2002, Patel et al., 2003, Do et al., 2007, Kulis et al., 2007, ReyesOrtiz et al., 2009). Our findings suggest that research should be conducted in all Latino ethnic groups to improve external validity of findings. Furthermore, research should focus on measuring the association between ethnic density and other HIV/AIDS outcomes (e.g., HIV testing, access to treatment), and evaluating if stigma or other mechanisms, such as acculturation and length of time in the US, may play a role. Results from such studies may lead to community-level interventions to utilize Latino ethnic density as a tool to understand and improve health among HIV-positive Latinos. Community involvement in HIV/AIDS related organizations and events has proven to 
decrease stigma, depression and loneliness in HIV-positive Latinos (Ramirez-Valles et al., 2005) and may be a starting point for future interventions.

\section{References}

Alvarez KJ, Levy BR. Health advantages of ethnic density for African American and Mexican American elderly individuals. Am J Public Health. 2012;102(12):2240-2.

Bécares L, Nazroo JY, Stafford M. The buffering effects of ethnic density on experienced racism and health. Health Place. 2009;15(3):670-8.

Becares L, Shaw R, Nazroo J, Stafford M, Albor C, Atkin K, et al. Ethnic density effect on physical morbidity, mortality, and health behaviors: a systematic review of the literature. Am J Public Health. 2012;102(12):e33-66.

Benjamins MR, Kirby JB, Bond Huie SA. County characteristics and racial and ethnic disparities in the use of preventive services. Prev Med. 2004;39(4):704-12.

Campos B, Ullman JB, Aguilera A, Dunkel Schetter C. Familism and psychological health: the intervening role of closeness and social support. Cultur Divers Ethnic Minor Pyschol. 2014;20(2):191-201.

Cantor AB. SAS survival analysis techniques for medical research, second edition. Cary, NC: SAS Institute Inc. 2003.

Catz SL, McClure JB, Jones GN, Brantley PJ. Predictors of outpatient medical appointment attendance among persons with HIV. AIDS Care. 1999;11(3):361-73.

Centers for Disease Control and Prevention. Guidelines for national human immunodeficiency virus case surveillance, including monitoring for human immunodeficiency virus infection and acquired immunodeficiency syndrome. MMWR Morb Mortal Wkly Rep. 1999;48(RR13):1-28.

Centers for Disease Control and Prevention. Revised surveillance case definitions for HIV infection among adults, adolescents, and children aged $<18$ months and for HIV infection and AIDS among children aged 18 months to $<13$ years --- United States, 2008. MMWR Morb Mortal Wkly Rep. 2008;57(RR-10):1-8.

Darrow WW, Montanea JE, Gladwin H. AIDS-related stigma among Black and Hispanic young adults. AIDS Behav. 2009;13(6):1178-88.

Das-Munshi J, Becares L, Dewey ME, Stanfield SA, Prince MJ. Understanding the effect of ethnic density on mental health: multi-level investigation of survey data from England. BMJ. 2010;341:c5367. 
Do DP, Dubowitz T, Bird CE, Lurie N, Escarce JJ, Finch BK. Neighborhood context and ethnicity differences in body mass index: a multilevel analysis using the NHANES III survey. Econ Hum Biol. 2007;5(2):179-203.

Edwards LV. Perceived social support and HIV/AIDS medication adherence among African American women. Qual Health Res. 2006;16(5):679-691.

Eschbach K, Mahnken J, Goodwin J. Neighborhood composition and incidence of cancer among Hispanics in the United States. Cancer. 2005;103(5):1036-44.

Eschbach K, Ostir GV, Patel KV, Markides KS, Goodwin JS. Neighborhood context and mortality among older Mexican Americans: Is there a barrio advantage?. Am J Public Health. 2004;94(10):1807-12.

Espinoza L, Hall HI, Hu X. Diagnoses of HIV infection among Hispanics/Latinos in 40 states and Puerto Rico, 2006-2009. J Acquir Immune Defic Syndr. 2012;60(2):205-13.

Espinoza L, Hall HI, Selik RM, Hu X. Characteristics of HIV infection among Hispanics, United States 2003-2006. J Acquir Immune Defic Syndr. 2008;49:94-101.

Franzini L, Spears W. Contributions of social context to inequalities in years of life lost to heart disease in Texas, USA. Soc Sci Med. 2003;57(10):1847-61.

Friedland J, Renwick R, McColl M. Coping and social support as determinants of quality of life in HIV/AIDS. AIDS Care. 1996;8(1):15-32.

Gerst K, Miranda PY, Eschbach K, Sheffield KM, Peek MK, Markides KS. Protective neighborhoods: neighborhood proportion of Mexican Americans and depressive symptoms in very old Mexican Americans. J Am Geriatr Soc. 2011;59(2):353-8.

Haas JS, Phillips KA, Sonneborn D, McCulloch CE, Baker LC, Kaplan CP, et al. Variation in access to health care for different racial/ethnic groups by racial/ethnic composition of individual's county of residence. Med Care. 2004;42(7):704-14.

Halpern D, Nazroo JY. The ethnic density effect: results from a national community survey of England and Wales. Int J Soc Psychiatry. 2000;46(1):34-46.

Hanna DB, Pfeiffer MR, Torian LV, Sackoff JE. Concurrent HIV/AIDS diagnosis increases the risk of short-term HIV-related death among persons newly diagnosed with AIDS, 2002-2005. AIDS Patient Care STDS. 2008;22(1):17-28.

Hong S, Zhang W, Walton E. Neighborhoods and mental health: exploring ethnic density, poverty, and social cohesion among Asian Americans and Latinos. Soc Sci Med. 2014;111:117-24. 
Inagami S, Borell LN, Wong MD, Fang J, Shapiro MF, Asch SM. Residential segregation and Latino, black and white mortality in New York City. J Urban Health. 2006;83(3):406-20.

Jenny AM, Schoendorf KC, Parker JD. The association between community context and mortality among Mexican American infants. Ethn Dis. 2001;11(4):722-31.

Kohl M, Heinze G. PSHREG: A SASr macro for proportional and nonproportional substribution hazards regression with competing risk data. Technical Report 08/2012. (http://cemsiis.meduniwien.ac.at/fileadmin/msi_akim/CeMSIIS/KB/programme/tr08_201 2-PSHREG.pdf). 2014. Retrieved April 2014.

Krieger N, Chen JT, Waterman PD, Scoobader MJ, Subramanian SV, Carson R. Geocoding and monitoring of US socioeconomic inequalities in mortality and cancer incidence: does the choice of area-based measures and geographic level matter?: The Public Health Disparities Geocoding Project. Am J Epidemiol. 2002;156(5):471-82.

Kulis S, Marsiglia F, Sicotte D, Nieri T. Neighborhood effects on youth substance use in a Southwestern city. Sociol Perspect. 2007;50(2):273-301.

Lanehart RE, Rodriguez de Gil P, Kim ES, Bellara AP, Kromrey JD, Lee RS. Propensity score analysis and assessment of propensity score approaches using SAS ${ }^{\circledR}$ procedures. SAS Global Forum 2012. (http://support.sas.com/resources/papers/proceedings12/3142012.pdf). 2012. Retrieved Feb 2015.

Lee M.A. Neighborhood residential segregation and mental health: a multilevel analysis on Hispanic Americans in Chicago. Soc Sci Med. 2009;68:1975-84.

Lopez-Class M, Perret-Gentil M, Kreling B, Caicedo L, Mandelblatt J, Graves KD. Quality of life among immigrant Latina breast cancer survivors: realities of culture and enhancing cancer care. J Cancer Educ. 2011;26(4):724-33.

Masi CM, Hawkley LC, Piotrowski ZH, Pickett KE. Neighborhood economic disadvantage, violent crime, group density, and pregnancy outcomes in a diverse, urban population. Soc Sci Med. 2007;65(12):2440-57.

Mason SM, Kaufman JS, Daniels JL, Emch ME, Hogan VK, Savitz DA. Neighborhood ethnic density and preterm birth across seven ethnic groups in New York City. Health Place. 2010;17:280-88.

Motel S, Patten E. The 10 largest Hispanic origin groups: characteristics, rankings, top counties. Pew Research Center. (http://www.pewhispanic.org/files/2012/06/The-10Largest-Hispanic-Origin-Groups.pdf). 2012.

National Center for Health Statistics. Health, United States, 2013: with special feature on prescription drugs. Hyattsville, MD. http://www.cdc.gov/nchs/data/hus/hus13.pdf. 2014. 
Ostir GV, Eschbach K, Markides KS, Goodwin JS. Neighbourhood composition and depressive symptoms among older Mexican Americans. J Epidemiol Community Health. 2003;57(12):987-92.

Patel KV, Eschbach K, Rudkin LL, Peek MK, Markides KS. Neighborhood context and self-rated health in older Mexican Americans. Ann Epidemiol. 2003;13(9):620-28.

Peak C, Weeks JR. Does community context influence reproductive outcomes of Mexican origin women in San Diego, California? J Immigr Health. 2002;4(3):125-36.

Pickett KE, Wilkinson RG. People like us: ethnic group density effects on health. Ethn Health. 2008;13(4):321-34.

Ramirez-Valles J, Fergus S, Reisen CA, Poppen PJ, Zea MC. Confronting stigma: community involvement and psychological well-being among HIV-positive Latino gay men. Hisp J Behav Sci. 2005;27:101-19.

Reyes-Ortiz CA, Ju H, Eschbach K, Kuo YF, Goodwin JS. Neighbourhood ethnic composition and diet among Mexican-Americans. Public Health Nutrition. 2009;12(12):2293-301.

Ritieni A, Moskowitz J, Tholandi M. HIV/AIDS misconceptions among Latinos: findings from a population-based survey of California adults. Health Educ Behav. 2008;35(2):245-59.

Ruiz JM, Steffen P, Smith TB. Hispanic mortality paradox: a systematic review and meta-analysis of the longitudinal literature. Am J Public Health. 2013;10(3):e52-60.

Schemper M, Wakouning S, Heinze S. The estimation of average hazard ratios by weighted Cox regression. Stat Med. 2009;28(19):2473-89.

Shaw RJ, Atkin K, Becares L, Albor CB, Stafford AM, Kiernan KE, et al. Impact of ethnic density on adult mental disorders: narrative review. Br J Psychiatry. 2012;201(1):11-19.

Shaw RJ, Pickett KE, Wilkinson RG. Ethnic density effects on birth outcomes and maternal smoking during pregnancy in the US Linked Birth and Infant Death data set. Am J Public Health. 2010;100(4):707-13.

Shaw RJ, Pickett KE. The association between ethnic density and poor self-rated health among US black and Hispanic people. Ethn Health. 2011;16(3):225-44.

Sheffield KM, Peek MK. Neighborhood context and cognitive decline in older Mexican Americans: Results from the Hispanic Established Populations for Epidemiologic Studies of the Elderly. Am J Epidemiol, 2009;169(9):1092-101. 
Smith R, Rossetto K, Peterson BL. A meta-analysis of dsclosure of one's HIV-positive status, stigma and social support. AIDS Care. 2008;20(10):1266-75.

Sturmer T, Schneeweiss S, Avorn J, Glynn RJ. Adjusting effect estimates for unmeasured confounding with validation data using propensity score calibration. Am J Epidemiol. 2005;162(3):279-89.

Swindells S, Mohr J, Justis JC, Berman S, Squier C, Wagener MM, et al. Quality of life in patients with human immunodeficiency virus infection: impact of social support, coping style and hopelessness. Int J STD AIDS. 1999;10(6):383-91.

Taylor BS, Reyes E, Levine EA, Khan SZ, Garduno LS, Donastorg Y, et al. Patterns of geographic mobility predict barriers to engagement in HIV care and antiretroviral treatment adherence. AIDS Patient Care STDS. 2014;28(6):284-95.

US Census Bureau. 2011 American Community Survey 5-year estimates. Available at: http://factfinder2.census.gov. 2014. Retrieved Jan 2014.

US Census Bureau. Geography: ZIP Code Tabulation Areas (ZCTAs). Available at: http://www.census.gov/geo/reference/zctas.html. 2013. Retrieved April 2013.

Varas-Diaz N, Serrano-Garcia I, Toro-Alfonso J. AIDS-related stigma and social interaction: Puerto Ricans living with HIV/AIDS. Qualit Health Res. 2005;15(2):169-87.

White K, Haas JS, Williams DR. Elucidating the role of place in health care disparities: the example of racial/ethnic residential segregation. Health Serv Res. 2012;47(3):127899.

Whitley R, Prince M, McKenzie K, Stewart R. Exploring the ethnic density effect: a qualitative study of a London electoral ward. Int J Soc Psychiatry. 2006;52(4):376-91.

Zee MC, Reisen CA, Poppen PJ, Echeverry JJ, Bianchi FT. Disclosure of HIV-positive status to Latino gay men’s social network. Am J Community Psychol. 2004; 33(1-2):10716. 
Tables and figures

TABLE 1- Latinos age 13 and older diagnosed with HIV infection by birth country/region and selected characteristics, Florida, 2005-2008

\begin{tabular}{|c|c|c|c|c|c|c|c|c|}
\hline & All Latinos & $\begin{array}{l}\text { U.S.-born } \\
\text { Latino } \\
\end{array}$ & Puerto Rico & Mexico & Cuba & $\begin{array}{c}\text { Central } \\
\text { America }\end{array}$ & $\begin{array}{c}\text { South } \\
\text { America }{ }^{b}\end{array}$ & Other $^{c}$ \\
\hline Total (n) $^{a}$ & 4649 & 1506 (32.4\%) & 396 (8.5\%) & $\begin{array}{r}324 \\
(7.0 \%) \\
\end{array}$ & $\begin{array}{r}754 \\
(16.2 \%) \\
\end{array}$ & $\begin{array}{r}480 \\
(10.3 \%) \\
\end{array}$ & 595 (12.8\%) & $\begin{array}{c}594 \\
(12.8 \%) \\
\end{array}$ \\
\hline $\begin{array}{l}\text { Individual-level va } \\
\text { Year of HIV } \\
\text { diagnosis }\end{array}$ & n (\%) & & & & & & & \\
\hline $\begin{array}{l}2005 \\
2006 \\
2007 \\
2008\end{array}$ & $\begin{array}{l}1162(25.0) \\
1122(24.1) \\
1225(26.4) \\
1140(24.5)\end{array}$ & $\begin{array}{l}382(25.4) \\
366(24.3) \\
385(25.6) \\
373(24.8)\end{array}$ & $\begin{array}{r}90(22.7) \\
105(26.5) \\
111(28.0) \\
90(22.7)\end{array}$ & $\begin{array}{l}80(24.7) \\
88(27.2) \\
88(27.2) \\
68(21.0)\end{array}$ & $\begin{array}{l}200(26.5) \\
162(21.5) \\
183(24.3) \\
209(27.7)\end{array}$ & $\begin{array}{l}124(25.8) \\
121(25.2) \\
119(24.8) \\
116(24.2)\end{array}$ & $\begin{array}{l}174(29.2) \\
144(24.2) \\
159(26.7) \\
118(19.8)\end{array}$ & $\begin{array}{l}112(18.9) \\
136(22.9) \\
180(30.3) \\
166(28.0)\end{array}$ \\
\hline $\begin{array}{l}\text { Sex at birth } \\
\text { Male } \\
\text { Female }\end{array}$ & $\begin{array}{r}3714(79.9) \\
935(20.1)\end{array}$ & $\begin{array}{r}1,140(75.7) \\
366(24.3)\end{array}$ & $\begin{array}{l}280(70.7) \\
116(29.3)\end{array}$ & $\begin{array}{r}284(87.7) \\
40(12.4)\end{array}$ & $\begin{array}{r}692(91.8) \\
62(8.2)\end{array}$ & $\begin{array}{l}345(71.9) \\
135(28.1)\end{array}$ & $\begin{array}{r}502(84.4) \\
93(15.6)\end{array}$ & $\begin{array}{l}471(79.3) \\
123(20.7)\end{array}$ \\
\hline $\begin{array}{l}\text { Age group at diagno } \\
\text { 13-19 years } \\
\text { 20-39 years } \\
40-59 \text { years } \\
60 \text { years or older }\end{array}$ & $\begin{array}{r}114(2.5) \\
2381(51.2) \\
1925(41.4) \\
229(4.9)\end{array}$ & $\begin{array}{r}67(4.5) \\
787(52.3) \\
599(39.8) \\
53(3.5)\end{array}$ & $\begin{array}{r}8(2.0) \\
167(42.2) \\
196(49.5) \\
25(6.3)\end{array}$ & $\begin{array}{r}8(2.5) \\
217(67.0) \\
88(27.2) \\
11(3.4)\end{array}$ & $\begin{array}{r}7(0.9) \\
301(39.9) \\
373(49.5) \\
73(9.7)\end{array}$ & $\begin{array}{r}11(2.3) \\
328(68.3) \\
131(27.3) \\
10(2.1)\end{array}$ & $\begin{array}{r}8(1.3) \\
327(55.0) \\
241(40.5) \\
19(3.2)\end{array}$ & $\begin{array}{r}5(0.8) \\
254(42.8) \\
297(50.0) \\
38(6.4)\end{array}$ \\
\hline $\begin{array}{l}\text { Mode of transmissi } \\
\text { IDU } \\
\text { MSM } \\
\text { MSM/IDU } \\
\text { Heterosexual } \\
\text { Other/unknown }\end{array}$ & $\begin{array}{r}267(5.7) \\
2483(53.4) \\
129(2.8) \\
1164(25.0) \\
606(13.0)\end{array}$ & $\begin{array}{r}125(8.3) \\
772(52.3) \\
48(3.2) \\
386(25.6) \\
175(11.6)\end{array}$ & $\begin{array}{r}77(19.4) \\
146(36.9) \\
20(5.1) \\
117(29.6) \\
36(9.1)\end{array}$ & $\begin{array}{r}8(2.5) \\
151(46.6) \\
7(2.2) \\
90(27.8) \\
68(21.0)\end{array}$ & $\begin{array}{r}19(2.5) \\
523(69.4) \\
25(3.3) \\
133(17.6) \\
54(7.2)\end{array}$ & $\begin{array}{r}6(1.3) \\
209(43.5) \\
11(2.3) \\
180(37.5) \\
74(15.4)\end{array}$ & $\begin{array}{r}10(1.7) \\
401(67.4) \\
10(1.7) \\
111(18.7) \\
63(10.6)\end{array}$ & $\begin{array}{r}22(3.7) \\
281(47.3) \\
8(1.4) \\
147(24.8) \\
136(22.9)\end{array}$ \\
\hline $\begin{array}{l}\text { HIV-to-AIDS interv } \\
\quad<1 \text { month }\end{array}$ & 1072 (23.1) & 310 (20.6) & 115 (29.0) & 113 (34.9) & 140 (18.6) & 139 (29.0) & 107 (18.0) & 148 (24.9) \\
\hline $\begin{array}{l}\text { Three-year survival } \\
\text { Alive }\end{array}$ & 4238 (91.2) & 1,394 (92.6) & 330 (83.3) & 290 (89.5) & $668(88.6)$ & 435 (90.6) & 565 (95.0) & 556 (93.6) \\
\hline
\end{tabular}


Length of survival in months

Median (range)

$57(0-83)$

$57(0-83)$

$55(0-83)$

$58(0-83)$

$55(0-83)$

$57(0-83)$

$59(0-83)$

$55(0-83)$

\section{ZCTA-level variables, $\mathbf{n}(\%)$}

Percent of population

below poverty line

(average 2007-2011),

quartiles

$$
\begin{aligned}
& <8.7 \\
& 8.7-12.9 \\
& 13.0-19.3 \\
& \geq 19.4
\end{aligned}
$$

Percent of population

16 and older who is

unemployed (average 2007-2011), quartiles

$$
\begin{aligned}
& <4.2 \\
& 4.2-5.5 \\
& 5.6-7.2 \\
& \geq 7.3
\end{aligned}
$$

339 (7.3)

1569 (33.8)

1748 (37.6)

$127(8.4)$
$325(21.6)$
$503(33.4)$

$29(7.3)$
$79(20.0)$

$21(6.5)$
$59(18.2)$

$140(35.4)$

$148(37.4)$

$107(33.0)$

137 (42.3)

$31(4.1)$
$150(19.9)$
$257(34.1)$
$316(41.9)$

$22(4.6)$

$74(15.4)$

$120(25.0)$

$264(55.0)$

$50(8.4)$

$153(25.7)$

267 (44.9)

$125(21.0)$

$59(9.9)$

$153(25.8)$

$175(29.5)$

$207(34.9)$

779 (16.8)

$886(19.1)$

$1206(25.9)$

$1778(38.2)$

$218(14.5)$
$264(17.5)$
$400(26.6)$
$624(41.4)$

47 (11.9)

36 (11.1)

$143(19.0)$

$175(23.2)$

$118(29.8) \quad 91(28.1) \quad 212(28.1)$

65 (13.5)

$111(23.1)$

$169(28.4)$

$113(19.0)$

$145(24.4)$

$168(28.2)$

$101(17.0)$

$106(17.9)$

624 (41.4)

$176(44.4) \quad 135(41.7)$

$224(29.7)$

206 (42.9)

Percent of population

18 years and older that

is a high school

graduate (average

2007-2011), quartiles

$\geq 92.1$

86.9-92.0

80.4-86.8

407 (8.8)

$828(17.8)$

$1382(29.7)$

2023 (43.7)

$155(10.3)$
$313(20.8)$
$483(32.1)$
$555(36.9)$

$33(8.3)$
$76(19.2)$
$126(31.8)$
$161(40.7)$

$25(7.7)$
$49(15.1)$
$94(29.0)$

$94(29.0)$
$156(48.2)$

$\begin{array}{rr}69(11.6) & 72(12.1) \\ 146(24.5) & 113(19.0) \\ 228(38.3) & 174(29.3) \\ 152(25.6) & 235(39.6)\end{array}$


Percent of population

who identified

themselves as

Hispanic/Latino (ethnic

density)

$$
\geq 50
$$

25-49

1708 (36.7)

426 (28.3)

95 (24.0)

$427(28.4)$

129 (32.6)

$72(22.2)$

$1338(28.8)$

653 (43.4)

$172(43.4) \quad 166(51.2)$

$\begin{array}{rr}502(66.6) & 222(46.3) \\ 191(25.3) & 121(25.2) \\ 61(8.1) & 137(28.5)\end{array}$

208 (35.0) $183(30.8)$

$197(33.1) \quad 187(31.5)$

Congruent Latino

origin for foreign born

individuals ${ }^{d}$

\begin{tabular}{|c|c|c|c|c|c|c|c|c|}
\hline No & 1541 (33.2) & --- & 242 (61.1) & $182(56.2)$ & 225 (29.8) & $480(100)$ & 412 (69.2) & --- \\
\hline Yes & 1008 (21.7) & & 154 (38.9) & 142 (43.8) & $529(70.2)$ & $0(0)$ & 183 (30.8) & \\
\hline
\end{tabular}

ZCTA, zip code tabulation area; IDU, injection drug use; MSM, male to male sexual contact. Percentage may not add up to 100 due to

rounding.

${ }^{a}$ Excludes cases diagnosed in a correctional facility $(\mathrm{n}=106)$, missing residential zip code at time of HIV diagnosis ( $\mathrm{n}=282$ ), missing month of

HIV diagnosis $(n=9)$, or diagnosed under the age of $13(n=14)$

${ }^{b}$ Includes 102 individuals reported as "Hispanic/Latino" and born in Brazil

${ }^{c}$ Individuals born in the Dominican Republic are included in the other Latino category $(\mathrm{n}=68)$

${ }^{d}$ Excludes U.S.-born Latinos and Latinos born in other Latino category

TABLE 2- Weighted multi-level Cox regression hazard ratios and 95\% confidence intervals for mortality among Latinos reported with HIV by birth country/region, 2005-2011

\begin{tabular}{|c|c|c|c|c|c|c|c|c|}
\hline \multicolumn{9}{|c|}{$\mathrm{aHR}^{a}$} \\
\hline & All Latinos & $\begin{array}{c}\text { U.S.-born } \\
\text { Latino } \\
\end{array}$ & Puerto Rico & Mexico & Cuba & $\begin{array}{c}\text { Central } \\
\text { America }\end{array}$ & $\begin{array}{c}\text { South } \\
\text { America }\end{array}$ & Other \\
\hline \multicolumn{9}{|c|}{ Individual-level variables } \\
\hline \multicolumn{9}{|c|}{ Year of HIV diagnosis } \\
\hline \multirow[t]{2}{*}{2005} & 1.49 & 1.32 & 1.07 & 3.72 & 1.55 & 1.45 & 4.25 & 2.35 \\
\hline & $(1.11-2.01)$ & $(0.75-2.39)$ & $(0.55-2.12)$ & $(0.90-26.00)$ & $(0.81-3.08)$ & $(0.60-3.65)$ & $(1.08-29.23)$ & $(0.86-7.13)$ \\
\hline 2006 & 1.29 & 1.48 & 0.74 & 2.94 & 0.94 & 1.31 & 2.22 & 1.44 \\
\hline \multirow[t]{2}{*}{2007} & 1.44 & 1.45 & 0.93 & 4.26 & 1.57 & 1.09 & 1.97 & 2.21 \\
\hline & $(1.06-1.97)$ & $(0.80-2.67)$ & $(0.47-1.88)$ & $(1.06-29.36)$ & $(0.82-3.10)$ & $(0.42-2.83)$ & $(0.42-14.39)$ & $(0.84-6.51)$ \\
\hline 2008 & Referent & Referent & Referent & Referent & Referent & Referent & Referent & Referent \\
\hline
\end{tabular}


Sex at birth

Male

Female

Age at diagnosis

(continuous/ 5 unit

increase)

Mode of transmission

Heterosexual

IDU $^{b}$

MSM

Other/unknown

HIV-to-AIDS interval

$<1$ month

$>1$ month

ZCTA-level variables

Percent of population

below poverty line

(average 2007-2011)

(continuous / 5 unit

increase)

Percent of population

who identified

themselves as

Hispanic/Latino (ethnic density)

$\geq 50$

25-49

$<25$

$\begin{array}{rrr}1.04 & 1.10 & 0.58 \\ (0.81-1.33) & (0.70-1.72) & (0.34-0.99) \\ \text { Referent } & \text { Referent } & \text { Referent } \\ & & \\ 1.26 & 1.31 & 1.26 \\ (1.22-1.31) & (1.23-1.41) & (1.13-1.41) \\ & & \\ \text { Referent } & \text { Referent } & \text { Referent } \\ 1.94 & 1.32 & 1.78 \\ (1.45-2.59) & (0.81-2.14) & (1.01-3.16) \\ 0.79 & 0.56 & 1.54 \\ (0.60-1.03) & (0.34-0.93) & (0.77-3.13) \\ 0.90 & 0.65 & 0.42 \\ (0.67-1.21) & (0.36-1.12) & (0.14-1.02) \\ & & \\ 2.86 & 2.41 & 2.77 \\ (2.38-3.43) & (1.70-3.38) & (1.79-4.29) \\ \text { Referent } & \text { Referent } & \text { Referent }\end{array}$

8.37

(1.64-156.32)

Referent

1.06
$(0.89-1.24)$

\section{Referent}

$\mathrm{N} / \mathrm{A}^{c}$

0.27

(0.10-0.70)

0.65

(0.25-1.61)

2.14

(0.99-4.69)

Referent
1.38
$(0.64-3.24)$
Referent

(0.46-3.19)

Referent

1.51

(1.38-1.65)

\section{Referent}

(1.31-6.82)

1.19

(0.66-2.26)

(0.34-1.87)

3.54

(2.26-5.51)

Referent
1.02
$(0.87-1.19)$

Referent

$\mathrm{N} / \mathrm{A}^{c}$

2.29

(0.87-6.75)

5.33

(2.12-14.24)

\subsection{3}

(2.20-7.55)

Referent
2.13

(0.54-9.58)

Referent

1.03

(0.84-1.25)

Referent

(0.04-7.44)

0.71

(0.23-2.69)

0.89

(0.21-3.49)

3.29

(1.46-7.21)

Referent
0.56

(0.26-1.20)

Referent

1.18

(1.03-1.35)

Referent

1.44

(0.39-4.20)

0.51

(0.20-1.29)

(0.24-1.36)

2.71

(1.44-5.08)

Referent

\begin{tabular}{|c|c|c|c|c|c|c|c|}
\hline $\begin{array}{r}1.14 \\
(1.09-1.20)\end{array}$ & $\begin{array}{r}1.05 \\
(0.96-1.15)\end{array}$ & $\begin{array}{r}1.21 \\
(1.08-1.34)\end{array}$ & $\begin{array}{r}1.08 \\
(0.88-1.32)\end{array}$ & $\begin{array}{r}1.12 \\
(1.00-1.25)\end{array}$ & $\begin{array}{r}1.18 \\
(1.01-1.37)\end{array}$ & $\begin{array}{r}1.39 \\
(1.12-1.70)\end{array}$ & $\begin{array}{r}1.07 \\
(0.88-1.28)\end{array}$ \\
\hline
\end{tabular}

\begin{tabular}{rrrrrrrr} 
Referent & Referent & Referent & Referent & Referent & Referent & Referent & Referent \\
0.88 & 0.88 & 0.61 & 0.73 & 1.19 & 0.55 & 1.05 & 0.65 \\
$(0.70-1.10)$ & $(0.56-1.39)$ & $(0.36-1.02)$ & $(0.19-2.66)$ & $(0.72-1.90)$ & $(0.23-1.18)$ & $(0.42-2.59)$ & $(0.28-1.45)$ \\
0.95 & 1.04 & 0.60 & 1.14 & 1.22 & 0.44 & 0.97 & 0.92 \\
$(0.76-1.18)$ & $(0.70-1.56)$ & $(0.37-0.99)$ & $(0.39-3.59)$ & $(0.50-2.55)$ & $(0.17-1.05)$ & $(0.38-2.43)$ & $(0.44-1.96)$ \\
\hline
\end{tabular}


ZCTA, zip code tabulation area; IDU, injection drug use; MSM, male to male sexual contact; HR, hazard ratio; aHR adjusted hazard ratio; CI, confidence interval.

${ }^{a}$ aHR adjusted for all variables in the column

${ }^{b}$ IDU and IDU/MSM categories have been combined to address small cell numbers

${ }^{c}$ Estimate not available due to small numbers of Latinos from that country of birth with IDU as a mode of HIV transmission 
TABLE 3- Weighted multi-level Cox regression hazard ratios and 95\% confidence intervals for mortality among Latinos reported with HIV by birth country/region, Florida, 2005-2011

\begin{tabular}{|c|c|c|c|c|}
\hline & $\begin{array}{c}\text { Model } 1 \\
\text { HR }(95 \% \text { CI) } \\
\end{array}$ & $\begin{array}{c}\text { Model } 2 \\
\text { aHR }(95 \% \text { CI) }\end{array}$ & $\begin{array}{c}\text { Model } 3 \\
\text { aHR }(95 \% \text { CI) } \\
\end{array}$ & $\begin{array}{c}\text { Model } 4 \\
\text { aHR (95\% CI) }\end{array}$ \\
\hline United States & Referent & Referent & Referent & Referent \\
\hline Puerto Rico & $2.71(2.09-3.51)$ & $1.99(1.53-2.59)$ & $2.00(1.53-2.59)$ & $2.00(1.53-2.59)$ \\
\hline Mexico & $0.97(0.64-1.41)$ & $1.01(0.67-1.49)$ & $0.89(0.59-1.32)$ & $0.90(0.59-1.32)$ \\
\hline Cuba & $26(0.96-1.64)$ & $1.21(0.92-1.59)$ & $.15(0.87-1.52)$ & $1.14(0.85-1.52)$ \\
\hline $\begin{array}{l}\text { Centr } \\
\text { Amer } \\
\text { South }\end{array}$ & $0.96(0.68-1.34)$ & $1.08(0.75-1.51)$ & $0.95(0.67-1.34)$ & $0.95(0.66-1.34)$ \\
\hline $\begin{array}{l}\text { America } \\
\text { Other }\end{array}$ & $\begin{array}{l}0.50(0.33-0.73) \\
0.74(0.52-1.04)\end{array}$ & $\begin{array}{l}0.57(0.37-0.83) \\
0.66(0.46-0.93)\end{array}$ & $\begin{array}{l}0.60(0.40-0.89) \\
0.67(0.47-0.94)\end{array}$ & $\begin{array}{l}0.60(0.40-0.89) \\
0.67(0.47-0.94)\end{array}$ \\
\hline $\begin{array}{l}\text { Model 2: M } \\
\text { diagnosis, se } \\
\text { Model 3: M } \\
\text { poverty (cor } \\
\text { Model 4: M }\end{array}$ & $\begin{array}{l}\text { is) } \\
\text { icludes country } \\
\text { icludes country }\end{array}$ & ion of birth, de & aphic variable & $\begin{array}{l}\text { (year of HIV } \\
\text { S interval) } \\
\text { I ZCTA-level } \\
\text { TA-level }\end{array}$ \\
\hline
\end{tabular}




\section{CONCLUSIONS}

To our knowledge this body of work is the first to identify neighborhood-level predictors of late HIV diagnosis and mortality for Latinos with HIV that go beyond rural/urban differences. It is also the first study to examine the role of Latino ethnic density on HIV/AIDS-related outcomes. Our findings suggest that HIV testing campaigns in areas with low educational attainment are not reaching Latino women and that areas with high unemployment might need to focus on decreasing testing barriers for men. Additionally, foreign-born Latinos in predominantly non-Latino areas appear to be at greater risk of late HIV diagnosis.

Our study also confirms disparities in mortality risk for Latinos with a history of IDU. Findings of that study suggest that high Latino ethnic density and rural residence increase the mortality risk for HIV-positive Latinos with a history of IDU. Furthermore, neighborhood poverty appears to be a strong predictor for mortality among Latinos without a history of IDU, but not for Latinos with a history of IDU.

Finally, our ethnic density study suggests that Latinos with HIV do not benefit from the protective effect of Latino ethnic density. Future research should focus on measuring the association between ethnic density and other HIV/AIDS outcomes (e.g., HIV testing, access to treatment), and evaluating if stigma or other mechanisms, such as acculturation and length of time in the US, may play a role. Results from such studies may lead to community-level interventions to utilize Latino ethnic density as a tool to understand and improve health among HIV-positive Latinos. 
VITA

DIANA MONTSERRAT SHEEHAN

Born, Guayaquil, Ecuador

2004-2007

B.S., Health Science

Boston University

Boston, Massachusetts

2008-2010

M.P.H, International Health

Boston University

Boston, Massachusetts

2008-2010

Clinical Research Coordinator

Boston University Medical School

Boston, Massachusetts

2010-2012

Program Manager

Community Based Care of Central Florida

Orlando, Florida

2012-2014

Student Scholar in Health Disparities

Center for Substance Use and AIDS Research on Latinos in the U.S. (C-SALUD)

Florida International University

Miami, Florida

2014-2015

Graduate Assistant

Florida International University

Miami, Florida

2015-present

Pre-doctoral Ruth L. Kirschtein Research Service Award Fellow

Center for Substance Use and AIDS Research on Latinos in the U.S. (C-SALUD)

Florida International University 
Miami, Florida

2013-present Doctoral Candidate

Florida International University

Miami, Florida

PUBLICATIONS (Selected)

Trepka MJ, Fennie KP, Sheehan DM, Lutfi K, Maddox LM, Lieb S. Late HIV diagnosis: differences by rural/urban residence, Florida, 2007-2011. AIDS Patient Care STDS. 2014;28(4): 188-197.

Sheehan DM, Trepka MJ, Dillon FR. Latinos in the United States on the HIV/AIDS care continuum by birth country/region: a systematic review of the literature. International Journal of STD \& AIDS. 2015;26(1):1-12.

Sastre F, Sheehan DM, Gonzalez A. Dating, marriage and parenthood for HIV-positive heterosexual Puerto Rican men: normalizing perspectives on everyday life with HIV. American Journal of Men’s Health. 2015;9(2):139-149.

Sheehan DM, Trepka MJ, Fennie K, Maddox LM. Rate of new HIV diagnoses among Latinos living in Florida: disparities by country/region of birth. AIDS Care. 2015;27(4):507-511.

Sheehan DM, Trepka MJ, Fennie KP, Prado G, Madhivanan P, Maddox L. Individual and neighborhood predictors of mortality among HIV-positive Latinos with a history of injection drug use, Florida, 2000-2011. Drug and Alcohol Dependence. 2015;154:243-50.

Sheehan DM, Trepka MJ, Fennie KP, Dillon FR, Madhivanan P, Maddox LM.

Neighborhood Latino ethnic density and mortality among HIV-positive Latinos by birth country/region, Florida, 2005-2008. Ethnicity \& Health. [Epub ahead of print].

Trepka MJ, Sheehan DM, Fennie KP, Niyonsenga T, Lieb S, Maddox LM. Completeness of HIV reporting on death certificates for Floridians reported with HIV infection 2000-2011. AIDS Care. [Epub ahead of print]

Sheehan DM, Trepka MJ, Fennie KP, Prado G, Maddox LM. Black-White Latino racial disparities in HIV survival, Florida, 2000-2011. International Journal of Environmental Research and Public Health. [in press] 